\title{
Total Synthesis and Biological Activities of (+)-Sulfamisterin (AB5366) and its Analogues
}

\author{
Hideyuki Sato, Takaki Maeba, Ryota Yanase, Akiko Yamaji-Hasegawa, \\ Toshihide Kobayashi, Noritaka Chida
}

Received: October 22, 2004 / Accepted: November 25, 2004

(C) Japan Antibiotics Research Association

\begin{abstract}
The first total synthesis of $(+)$-sulfamisterin (AB5366), a naturally occurring $\alpha$-substituted $\alpha$-amino acid derivative possessing a sulfonated hydroxy function, is described. Overman rearrangement of an allylic trichloroacetimidate derived from D-tartrate effectively generated the tetrasubstituted carbon containing a nitrogen substituent. Construction of the amino acid moiety and sulfonation of the hydroxy group, followed by deprotection completed the total synthesis, which fully confirmed the proposed absolute structure of the natural product. The possible stereoisomers of $(+)$-sulfamisterin and their desulfonated derivatives were also synthesized. Biological assessment of all synthetic compounds revealed that natural $(+)$-sulfamisterin and its 3-epimer as well as their desulfonated derivatives possessing $2 S$-configuration strongly inhibit the serine palmitoyl transferase both in vitro and in vivo, whereas compounds with $2 R-$ configuration were found to show much weaker inhibitory activity.
\end{abstract}

Keywords sulfamisterin, AB5366, total synthesis, sulfamisterin analogues, SPT inhibitory activity

\section{Introduction}

$(+)$-Sulfamisterin (AB5366 1) is an antifungal agent isolated from the culture broths of Pycnidiella sp. AB5366 in $1996[1,2]$ and reported to be an inhibitor of serine palmitoyl transferase (SPT) [3]. The structural study by spectral and X-ray crystallographic analysis showed that 1 has an $\alpha$-substituted $\alpha$-amino acid structure with a sulfonated hydroxy function [2] (Fig. 1). Compound 1 has a structure that resembles myriocin [4,5], a well-known SPT inhibitor as well as strong immunosuppressant. Recently, detailed SPT inhibitory activities of sulfamisterin and its simple analogues obtained by chemical transformation of the natural product have been reported [3]. With interest in the structure-activity relationship of sulfamisterin, we embarked on the synthesis of $\mathbf{1}$ and its possible stereoisomers $(\mathbf{2} \sim \mathbf{4})$. In this paper, we report the first total synthesis of $\mathbf{1}$ and its stereoisomers $(\mathbf{2} \sim \mathbf{4})$ as well as their desulfonated analogues $(\mathbf{5} \sim \mathbf{8})$ starting from tartrates using Overman rearrangement $[6,7]$ as the key transformation. SPT inhibitory activities both in vitro and in vivo of these compounds $(\mathbf{1} \sim \mathbf{8})$ are also reported.

\section{Results and Discussion}

Total Synthesis of (+)-Sulfamisterin and its C-3 Epimer

The known (2S,3S)-3-benzyloxybutane-1,2,4-triol [8] (9a) derived from diisopropyl D-tartrate in 2 step reaction, was treated with 2-methoxypropene in the presence of pyridinium $p$-toluenesulfonate (PPTS) to afford a mixture
N. Chida (Corresponding author), H. Sato, T. Maeda, R. Yanase: Department of Applied Chemistry, Faculty of Science and Technology, Keio University, 3-14-1, Hiyoshi, Kohoku-ku, Yokohama 223-8522, Japan, E-mail: chida@applc.keio.ac.jp
A. Yamaji-Hasegawa, T. Kobayashi: RIKEN, 2-1 Hirosawa, Wako, 351-0198, Japan 


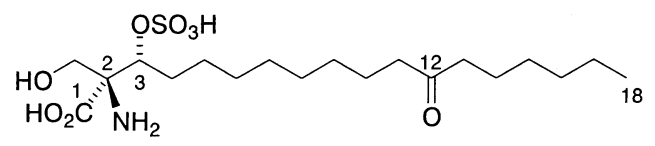

(+)-sulfamisterin (AB5366) (1)
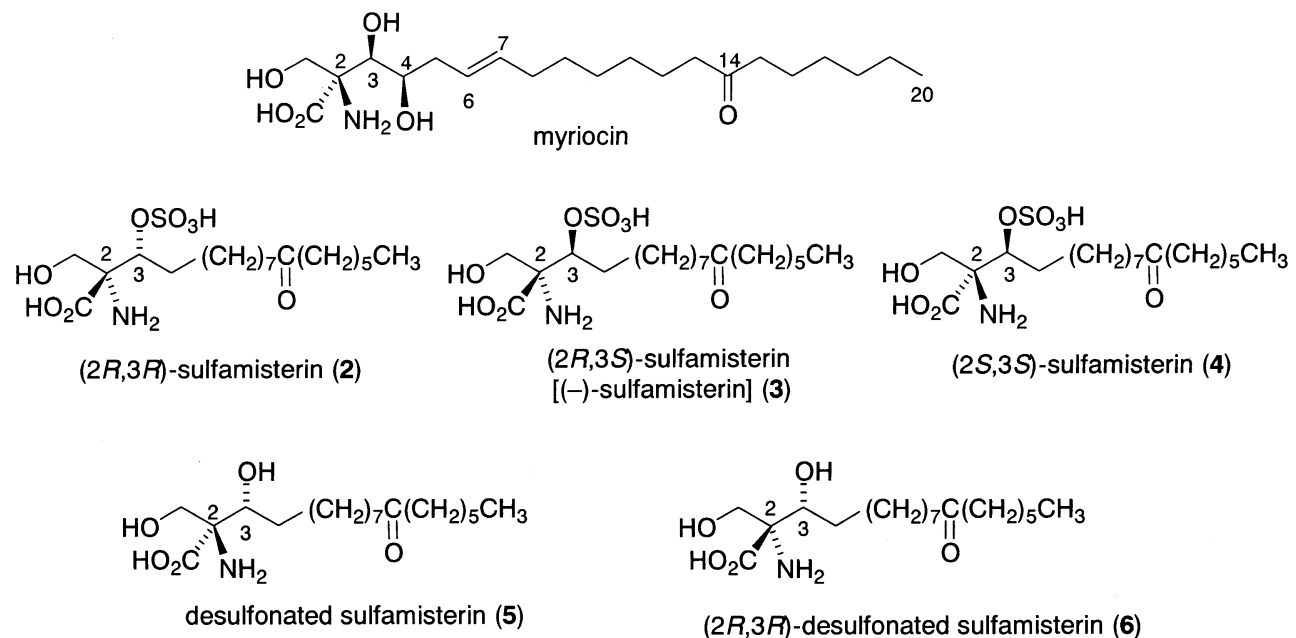

$(2 R, 3 R)$-desulfonated sulfamisterin (6)<smiles>CCCCCCCCCCCCCCCCCCC(N)(CO)C(=O)O</smiles>

(2R,3S)-desulfonated sulfamisterin (7)<smiles></smiles>

(2S,3S)-desulfonated sulfamisterin (8)

Fig. 1 Structures of (+)-sulfamisterin, myriocin and sulfamisterin analogues.

of the known acetonides [9] 10a, 11a and 12a (Scheme 1). Separation of the mixture by a silica gel chromatography afforded 10a in $27 \%$ isolated yield along with a mixture of 11a and 12a (68\% yield). Acid hydrolysis of a mixture of 11a and 12a gave the starting triol 9a in $87 \%$ yield, which could be reused to provide additional amount of 10a. Swern oxidation of 10a gave an aldehyde, which without purification, was reacted with Wittig reagent generated from phosphonium salt [10] $\mathbf{1 3}$ and $n$-BuLi to give 14a in $45 \%$ yield from 10a as a mixture of geometrical isomers $(E: Z=c a .1: 4)$. Catalytic hydrogenation of 14a afforded saturated alcohol 15a in $88 \%$ yield. The observed coupling constants in 15a $\left(J_{4,5}\right.$ and $\left.J_{5,6}<3.5 \mathrm{~Hz}\right)$ revealed the cis relationship of $\mathrm{C}-4$ and $\mathrm{C}-5$ substituents, supporting the assigned structure. PCC oxidation of 15a followed by reaction with $\mathrm{Ph}_{3} \mathrm{P}=\mathrm{CHCO}_{2}$ Et gave 16a as a single isomer in $97 \%$ yield. The observed NOE between a vinyl proton and $\mathrm{H}-4$ clearly suggested the $E$-geometry of the double bond. Diisobutylaluminum hydride (Dibal) reduction of 16a afforded allyl alcohol 17a in 95\% yield.

With the allylic alcohol 17a in hand, we then examined the Overman rearrangement. Thus, an $o$-xylene solution of allylic trichloroacetimidate 18a prepared from 17 a by the action of $\mathrm{CCl}_{3} \mathrm{CN}$ and 1,8-diazabicyclo[5.4.0]undec-7-ene
(DBU) was heated at $140^{\circ} \mathrm{C}$ in a sealed tube under argon in the presence of solid potassium carbonate [11] to afford the diastereomeric rearranged products, which were easily and cleanly separated by silica gel chromatography to provide 19a and 20a in 50 and $45 \%$ isolated yields, respectively. HPLC analysis of 20a and 20b (prepared from dimethyl Ltartrate, vide infra) with chiral column (chiralcel OD) showed that the optical purities of 20a and 20b are both $>99 \%$ ee, respectively, indicating no racemization had occurred during the transformation of 15a to 19a and 20a. The protecting group of nitrogen ( $N$-trichloroacetyl group) in 19a was converted into $N$-benzyloxycarbonyl (Cbz) group by two step reactions to give 21a, quantitatively. Similar treatment of 20a afforded 22a (97\% yield). NOE experiments of 21a and 22a clearly showed that the tetrasubstituted carbon in 21a possessed $S$ configuration whereas that in 22a is $R$ configuration, respectively.

Ozonolysis of 21a, followed by further oxidation and esterification, and subsequent acid hydrolysis afforded diol 23a in 50\% yield (Scheme 2). The primary hydroxy group in 23a was selectively protected as a benzyloxymethyl ether to give 24 a (64\% yield), whose remaining hydroxy group was sulfonated by the action of $\mathrm{SO}_{3}$-pyridine [12] to afford 25a, quantitatively. Hydrogenolysis of 25a in the presence 

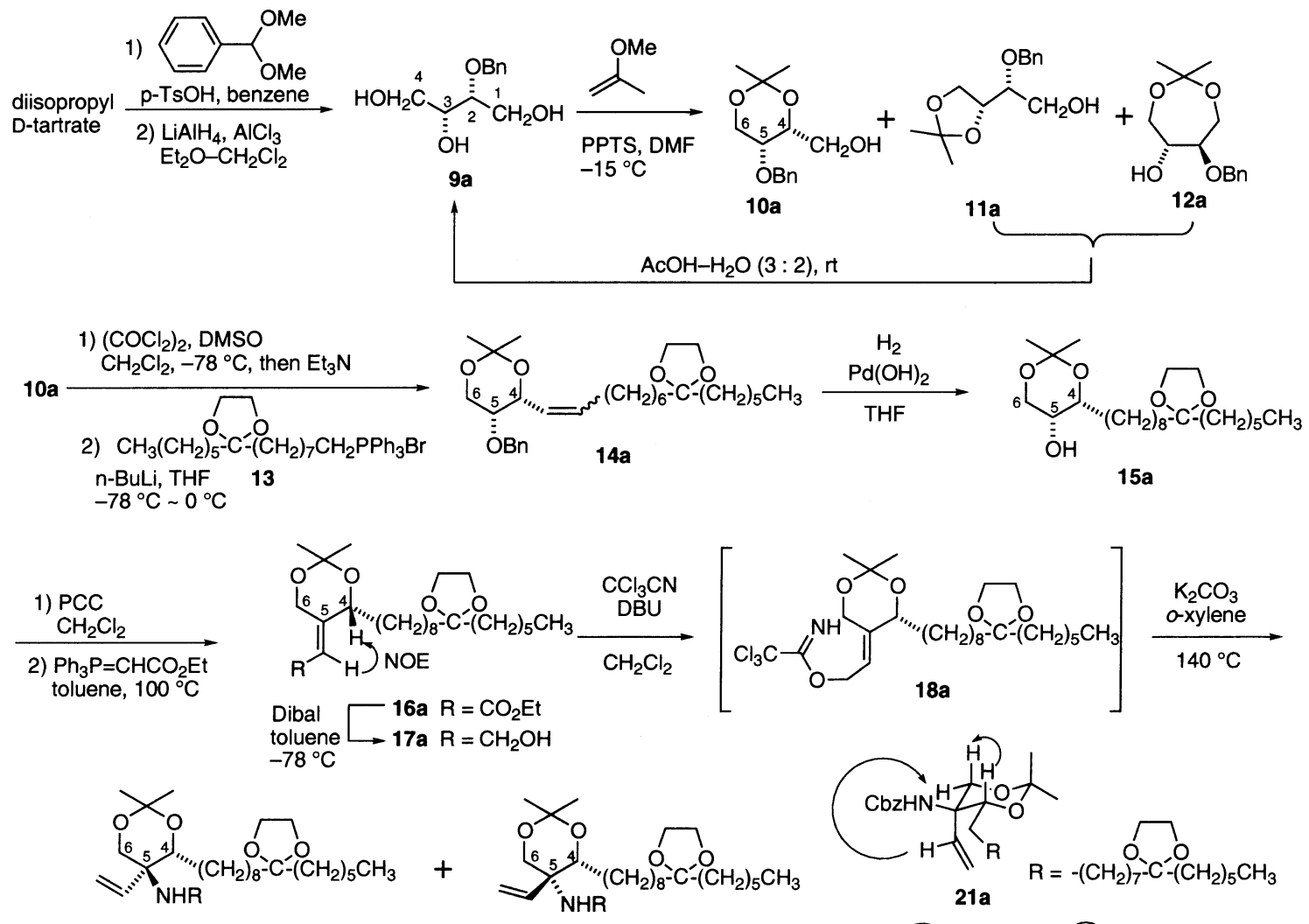
1) Dibal
toluene $19 \mathrm{a} \mathrm{R}=-\mathrm{COCCl}_{3}$
2) $\stackrel{-78^{\circ} \mathrm{C}}{\mathrm{CbzCl}} \longrightarrow 21 \mathrm{a} \mathrm{R}=-\mathrm{Cbz}$
$\mathrm{NaHCO}_{3}$
dioxane

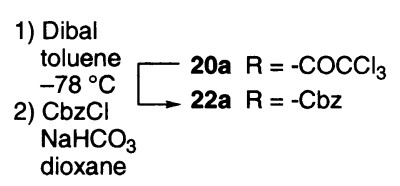
$\mathrm{CbzCl}$

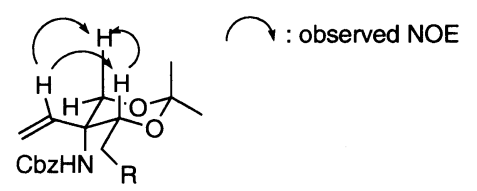

22a

Scheme 1

$\mathrm{Bn}=-\mathrm{CH}_{2} \mathrm{Ph}, \mathrm{Cbz}=-\mathrm{C}(\mathrm{O}) \mathrm{OCH}_{2} \mathrm{Ph}$.

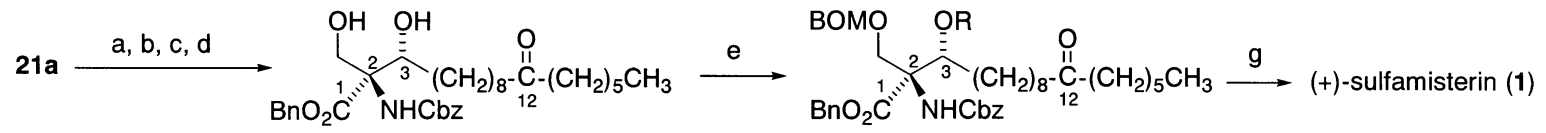

$$
\begin{aligned}
& \text { 23a }
\end{aligned}
$$

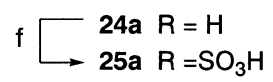

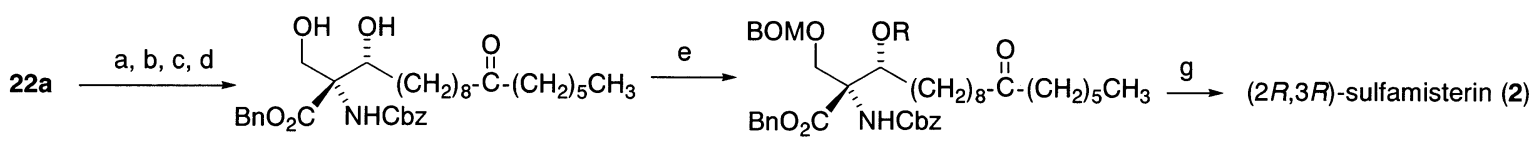

$$
\begin{aligned}
& \text { 26a }
\end{aligned}
$$

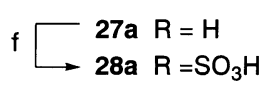

Scheme 2

$\mathrm{BOM}=-\mathrm{CH}_{2} \mathrm{OCH}_{2} \mathrm{Ph}$. Reagents and conditions: (a) $\mathrm{O}_{3}, \mathrm{EtOH},-78^{\circ} \mathrm{C}$ then $\mathrm{Me}_{2} \mathrm{~S}$; (b) $\mathrm{NaClO}_{2}, \mathrm{NaH}_{2} \mathrm{PO}_{4}, \mathrm{HOSO}_{2} \mathrm{NH}_{2}, t-\mathrm{BuOH}_{2} \mathrm{H}_{2} \mathrm{O}$; (c) $\mathrm{BnOH}, \mathrm{N}$-ethyl-N'-(3-dimethylaminopropyl)carbodiimide (WSCD), DMAP, $\mathrm{CH}_{2} \mathrm{Cl}_{2}$; (d) $\mathrm{AcOH}-\mathrm{H}_{2} \mathrm{O}(3: 2) ;\left(\right.$ e) $\mathrm{BOMCl}^{2}, \mathrm{Pr}_{2} \mathrm{NEt} \mathrm{CH}_{2} \mathrm{Cl}_{2}, 40^{\circ} \mathrm{C}$; (f) $\mathrm{SO}_{3}$-pyridine complex, pyridine, $80^{\circ} \mathrm{C}$; (g) $\mathrm{H}_{2}, \mathrm{Pd}(\mathrm{OH})_{2}, \mathrm{MeOH}$. 
of $\mathrm{Pd}(\mathrm{OH})_{2}$, followed by treatment with weak acidic resin (IRC-76, $\mathrm{H}^{+}$form) and purification with LH-20 provided (+)-sulfamisterin (1) in 57\% yield. The spectral $\left({ }^{1} \mathrm{H}\right.$ and ${ }^{13} \mathrm{C}$ NMR) data for synthetic $\mathbf{1}$ were fully identical with those of natural $(+)$-sulfamisterin, and the $[\alpha]_{\mathrm{D}}$ value of synthetic 1 showed good agreement $\left\{[\alpha]_{\mathrm{D}}^{25}+3.6^{\circ}(c) 0.62\right.$, $\mathrm{MeOH})\}$ with that of natural product $\left\{[\alpha]_{\mathrm{D}}^{23}+2.0^{\circ}(c 1.0\right.$, $\mathrm{MeOH})[1] ;[\alpha]_{\mathrm{D}}^{23}+3.1^{\circ}(c 0.50, \mathrm{MeOH})$, measured in our laboratory $\}$. Therefore, total synthesis of $(+)$-sulfamisterin has been accomplished, confirming the proposed absolute structure of the natural product.

Similar treatment of 22a as described for the preparation of 1 from 21a afforded (2R,3R)-sulfamisterin (2), a C-3 epimer of natural sulfamisterin, in 7 step reactions and in $58 \%$ overall yield from 22a.

\section{Preparation of Sulfamisterin Analogues}

To obtain information of the biological role of the sulfate function, synthesis of desulfonated analogues of sulfamisterin was carried out (Scheme 3). Thus, ozonolysis of 19a, followed by oxidation and esterification, and subsequent deprotection of an acetonide and a ketal groups by acid hydrolysis afforded 29a in 57\% yield. Saponification of 29a with $12 \%$ aqueous $\mathrm{NaOH}-\mathrm{MeOH}$ followed by neutralization with acidic resin (IRC-76) furnished desulfonated sulfamisterin (5) in 53\% yield. Similar treatment of 20a afforded $(2 R, 3 R)$-desulfonated sulfamisterin (6).

The enantiomers of 1, 2, 5 and 6 were synthesized starting from dimethyl L-tartrate (Scheme 4). Thus, the same reaction sequences as used for preparation of $19 \mathrm{a}$ and 20a from diisopropyl D-tartrate were applied to dimethyl Ltartrate to give a diastereomeric pair of $\mathbf{1 9 b}$ (enantiomer of 19a) and 20b (enantiomer of 20a). By the same reactions as employed for preparation of 1 and 5 from 19a, one of rearranged product $19 \mathrm{~b}$ was successfully transformed into (-)-sulfamisterin (3) and (2R,3S)-desulfonated sulfamisterin (7). Similar transformation of another rearranged product $\mathbf{2 0 b}$ provided $(2 S, 3 S)$-sulfamisterin (4) and $(2 S, 3 S)$-desulfonated sulfamisterin $(\mathbf{8})$.

\section{Biological Activities}

The inhibitory activities of synthetic compounds against SPT were measured according to a method described previously [3]. The results were shown in Table 1 and 2. The in vitro assay with the Chinese hamster ovary $(\mathrm{CHO})$ cell homogenates by measuring the radioactivity of incorporated $\left[{ }^{3} \mathrm{H}\right]$-serine revealed that $(+)$-sulfamisterin (1) (possessing $2 S, 3 R$ absolute configuration) strongly inhibit the SPT activity. Interestingly, 3-epi-(+)-sulfamisterin (4) as well as derivatives without a sulfate function, desulfonated sufamisterin (5) and $(2 S, 3 S)$-desulfonated sufamisterin (8) were found to be also strong inhibitors. However, compounds with $2 R$ configuration $(\mathbf{2}, \mathbf{3}, \mathbf{6}$ and $\mathbf{7})$ showed much weaker inhibitory activity. This tendency was

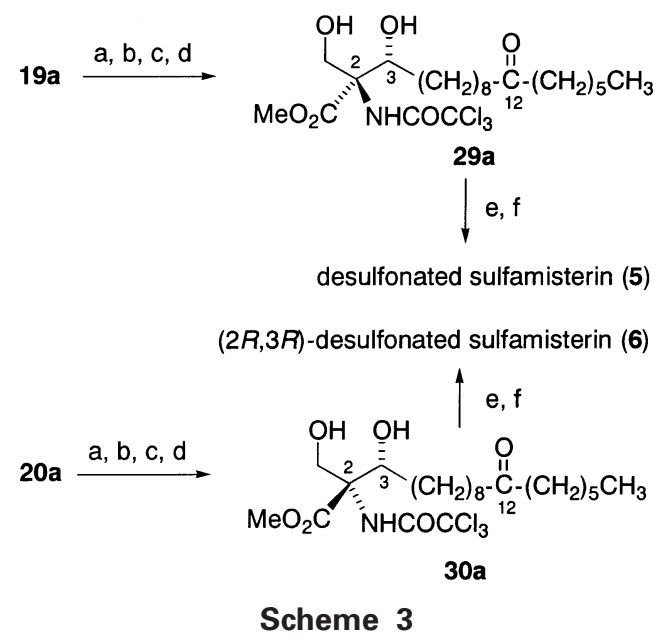

Reagents and conditions: (a) $\mathrm{O}_{3}, \mathrm{EtOH},-78^{\circ} \mathrm{C}$ then $\mathrm{Me}_{2} \mathrm{~S}$; (b) $\mathrm{NaClO}_{2}, \quad \mathrm{NaH}_{2} \mathrm{PO}_{4}, \quad \mathrm{HOSO}_{2} \mathrm{NH}_{2}, \quad t-\mathrm{BuOH}-\mathrm{H}_{2} \mathrm{O}$; (c) $\mathrm{Me}_{3} \mathrm{SiCHN}_{2}$, $\mathrm{MeOH}$-benzene; (d) $6 \mathrm{M} \mathrm{HCl}$ aq-THF (1:2), rt; (e) $12 \% \mathrm{NaOH}$ aq$\mathrm{MeOH}(1: 2)$; (f) IRC-76 resin ( $\mathrm{H}^{+}$form).

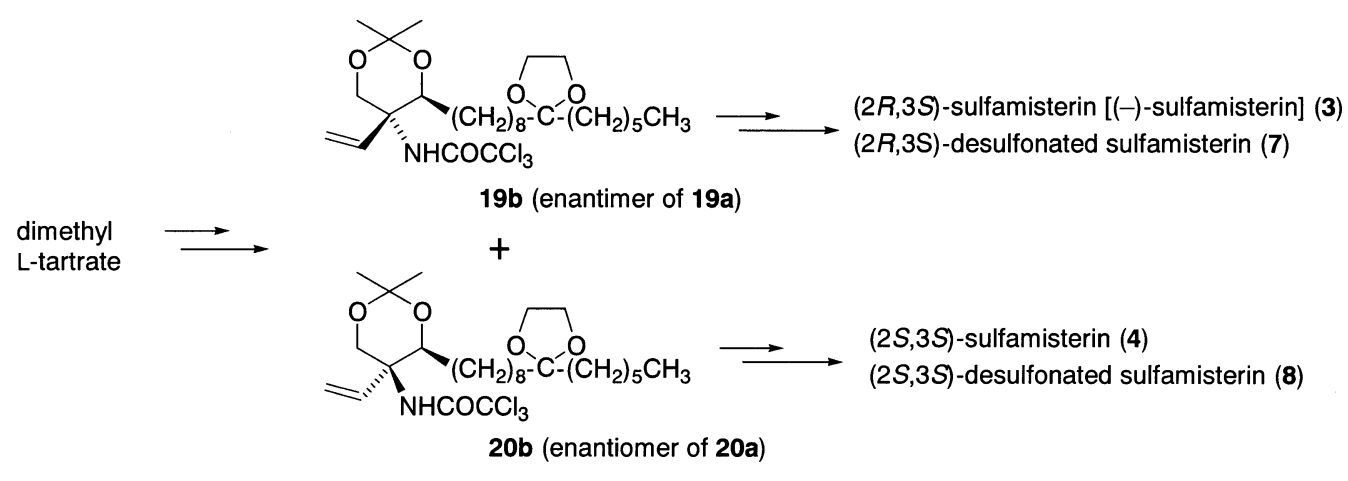

Scheme 4 
also observed in in vivo assay in which the amount of several sphingolipids synthesized by $\mathrm{CHO}$ cells were measured. Whereas compounds possessing $2 S$ configuration $(\mathbf{1}, \mathbf{4}, \mathbf{5}$ and $\mathbf{8})$ inhibited the biosynthesis of sphingomyelin, glucosylceramide and ceramide with a concentration as low as $11.25 \mu \mathrm{M}$, compounds with $2 R$ configuration $(\mathbf{2}, \mathbf{3}, \mathbf{6}$ and 7$)$ were found to be weaker than those with $2 S$ configuration. The fact that all compounds did not inhibit the synthesis of phosphatidylethanolamine and phosphatidylserine as well as previous results [3] suggested that sulfamistein and its analogues suppress sphingolipid biosynthesis through the inhibition of SPT. These results revealed that in sulfamisterin-type compounds, 1) the $2 S$ configuration is essential for the high SPT inhibitory activity; 2) the configuration at C-3 is not an important factor; and 3) sulfonation of a hydroxy function at C-3 does not significantly affect the activity. These findings should be important and useful for the design of new SPT inhibitors.

Table 1 The activity of SPT (\%) measured in the presence of compounds $\mathbf{1} \sim \mathbf{8}$ in vitro at various concentrations. ${ }^{a}$

\begin{tabular}{cccrc}
\hline & \multicolumn{5}{c}{ Concentration } \\
\cline { 2 - 5 } Compound & $100 \mu \mathrm{M}$ & $10 \mu \mathrm{M}$ & $1 \mu \mathrm{M}$ & $0.01 \mu \mathrm{M}$ \\
\hline $\mathbf{1}$ & 3.7 & 3.0 & 4.0 & 18.1 \\
$\mathbf{2}$ & 3.5 & 9.0 & 35.6 & 98.3 \\
$\mathbf{3}$ & 3.8 & 7.2 & 30.0 & 99.9 \\
$\mathbf{4}$ & 2.8 & 3.0 & 3.5 & 18.4 \\
$\mathbf{5}$ & 3.3 & 6.5 & 5.4 & 27.5 \\
$\mathbf{6}$ & 4.0 & 7.0 & 30.5 & 98.1 \\
$\mathbf{7}$ & 4.8 & 12.5 & 39.1 & 98.8 \\
$\mathbf{8}$ & 2.5 & 4.2 & 3.7 & 11.3 \\
\hline
\end{tabular}

${ }^{a} \mathrm{CHO}$ cell homogenates were treated with compounds at the concentration indicated in the reaction buffer containing palymitoyl $\mathrm{CoA}$ and $\left[{ }^{3} \mathrm{H}\right]$-serine at $37^{\circ} \mathrm{C}$ for 20 minutes. The observed relative radioactivities, measured with a liquid scintillation counter $(\%$, the amount when the assay was carried out without compounds corresponds to 100\% SPT activity) of the lipid products extracted from the reaction mixture, are shown. The activity without palmitoyl CoA was considered as $0 \%$. For detailed experimental procedures, see ref. 3 .

Table 2 Inhibition of sphingolipid synthesis in vivo by compounds $\mathbf{1} \sim \mathbf{8}^{\text {a }}$

\begin{tabular}{|c|c|c|c|c|c|}
\hline Compound & $\mathrm{SM}^{\mathrm{b}}$ & $\mathrm{GlcCer}^{\mathrm{c}}$ & $\operatorname{Cer}^{d}$ & $\mathrm{PS}^{\mathrm{e}}$ & $P E^{f}$ \\
\hline 1 & $13.5(23.7)$ & $6.2(3.4)$ & $3.0(3.2)$ & $88.2(104.0)$ & 95.9 (91.4) \\
\hline 2 & $96.5(95.5)$ & $103.3(74.1)$ & $94.6(79.2)$ & $101.1(116.2)$ & $107.0(107.7)$ \\
\hline 3 & $90.8(36.8)$ & $101.9(11.5)$ & $100.2(2.3)$ & 97.5 (105.9) & $101.5(99.0)$ \\
\hline 4 & $19.3(25.4)$ & $5.6(5.5)$ & $6.9(2.3)$ & 92.5 (105.9) & $92.0(99.0)$ \\
\hline 5 & $12.4(23.4)$ & $0.6(1.9)$ & $2.8(1.8)$ & 89.5 (98.8) & $86.9(92.1)$ \\
\hline 6 & $104.1(126.0)$ & $111.2(89.4)$ & $113.0(88.7)$ & 98.2 (108.8) & 109.6 (125.9) \\
\hline 7 & 89.9 (138.6) & $88.1(139.2)$ & $100.1(154.7)$ & 89.1 (114.0) & 94.4 (129.9) \\
\hline 8 & $12.9(28.4)$ & $2.4(3.9)$ & $3.2(2.5)$ & $94.2(106.7)$ & $90.5(102.2)$ \\
\hline
\end{tabular}

${ }^{a} \mathrm{CHO}$ cells were treated with compounds overnight at the concentration of $11.25 \mu \mathrm{M}$ and then cells were labeled with [ $\left.{ }^{14} \mathrm{C}\right]$-serine for 2 hours. Newly synthesized lipids were analyzed and their observed relative radioactivities (\%, the amount when cells were cultured without compounds corresponds to $100 \%$ ) are shown (numbers in parentheses denote the activities measured at the concentration of $45 \mu \mathrm{M}$ ). For detailed experimental procedures, see ref. $3 .{ }^{b}$ sphingomyerin. ${ }^{c}$ glucosylceramide. ${ }^{d}$ ceramide. ${ }^{e}$ phosphatidylserine. ${ }^{f}$ phosphatidylethanolamine. 


\section{Experimental}

\section{General}

IR spectra were taken with a JASCO FT/IR-200 spectra. Mass spectra are recorded on a JEOL GC Mate spectrometer with EI $(70 \mathrm{eV})$ or FAB mode. Melting points were determined on a Mitamura-Riken micro hot stage. Optical rotations were recorded using a sodium lamp with a JASCO DIP-370 instrument with $1 \mathrm{dm}$ tube. ${ }^{1} \mathrm{H}$ (at $300 \mathrm{MHz}$ ) and ${ }^{13} \mathrm{C}$ NMR (at $75 \mathrm{MHz}$ ) spectra were measured with JEOL JNM Lambda $300(300 \mathrm{MHz})$ or Varian MVX-300 (300 MHz) spectrometers. Chemical shifts are reported as $\delta$ values in ppm relative to tetramethylsilane or chloroform as internal references. Organic extracts were dried over $\mathrm{Na}_{2} \mathrm{SO}_{4}$ and concentrated below $40^{\circ} \mathrm{C}$ under reduced pressure. For column chromatography, Merck silicagel $60(230 \sim 400$ or $75 \sim 230$ mesh) was used, unless otherwise noted. Preparative TLC was performed on precoated Merck PLC plate (silicagel 60 F254 on glass plates, $0.25 \mathrm{~mm}$ ).

\section{2-O-Benzyl-D-threitol (9a)}

To a solution of diisopropyl D-tartrate $(9.0 \mathrm{~g}, 38.4 \mathrm{mmol})$ in $90 \mathrm{ml}$ of benzene at room temperature were added benzaldehyde dimethyl acetal $(6.35 \mathrm{ml}, 42.3 \mathrm{mmol})$ and 10 camphorsulfonic acid (CSA, $446 \mathrm{mg}, 1.92 \mathrm{mmol}$ ), and the mixture was heated at reflux for 2 days. After cooling, the reaction mixture was neutralized with $\mathrm{Et}_{3} \mathrm{~N}(0.3 \mathrm{ml})$ and diluted with EtOAc. The resulting mixture was washed with water and dried. Removal of the solvent gave a residue, which was purified by column chromatography (200 g silica gel, 1/1 EtOAc/hexane as an eluent) to afford a benzylidene derivative (13.5 g, quant.) as a pale yellow syrup. To a suspension of $\mathrm{LiAlH}_{4}(5.55 \mathrm{~g}, 146 \mathrm{mmol})$ in diethyl ether $(80 \mathrm{ml})$ and $\mathrm{CH}_{2} \mathrm{Cl}_{2}(75 \mathrm{ml})$ was added the benzylidene derivative $(13.5 \mathrm{~g}, 38.4 \mathrm{mmol})$ at $0^{\circ} \mathrm{C}$. After stirring at $0^{\circ} \mathrm{C}$ for 40 minutes, to the reaction mixture was added $\mathrm{AlCl}_{3}(16.7 \mathrm{~g}, 125 \mathrm{mmol})$ in diethyl ether $(80 \mathrm{ml})$ dropwise at $0^{\circ} \mathrm{C}$, and the mixture was heated at reflux for 2.5 hour. After cooling to $0^{\circ} \mathrm{C}$, to the mixture were added with water $(20 \mathrm{ml}), 15 \mathrm{wt} \% \mathrm{NaOH}$ aq $(100 \mathrm{ml})$ and water $(25 \mathrm{ml})$. The insoluble material was removed by filtration through celite (THF as an eluent), and the filtrate was dried. Removal of the solvent afforded crystalline residue, which was recrystallized from benzene to give 9a $(5.6 \mathrm{~g}, 63 \%)$ as white crystals; m.p. $74 \sim 75^{\circ} \mathrm{C} ;[\alpha]_{\mathrm{D}}^{23}-15^{\circ}(c 0.92, \mathrm{MeOH})$ \{lit. [8] m.p. $75 \sim 76^{\circ} \mathrm{C}$; $\left.[\alpha]_{\mathrm{D}}^{23}-15^{\circ}(c 0.96, \mathrm{MeOH})\right\}$; IR $v_{\max }(\mathrm{KBr}$ disc) 3200 3400, 2940, 2900, 1450, 1330,
$1200,1125,1090,1050,1035,990 \mathrm{~cm}^{-1}$; HR FAB-MS $\mathrm{m} / \mathrm{z}$ for $\mathrm{C}_{11} \mathrm{H}_{17} \mathrm{O}_{4}(\mathrm{M}+\mathrm{H})^{+}$, Calcd: 213.1127, Found: 213.1126; ${ }^{1} \mathrm{H}$ NMR $\left(300 \mathrm{MHz}, \mathrm{CDCl}_{3}\right) \delta: 2.40(1 \mathrm{H}, \mathrm{bt}, J=5.4 \mathrm{~Hz}$, primary $\mathrm{OH}), 2.59(1 \mathrm{H}, \mathrm{bt}, J=6.6 \mathrm{~Hz}$, primary $\mathrm{OH}), 2.86$ $(1 \mathrm{H}, \mathrm{d}, J=5.7 \mathrm{~Hz}$, secondary $\mathrm{OH}), 3.55 \sim 3.59(1 \mathrm{H}, \mathrm{m}, \mathrm{H}-$ 3), $3.64 \sim 3.92(5 \mathrm{H}, \mathrm{m}, \mathrm{H}-1, \mathrm{H}-2, \mathrm{H}-4), 4.59(1 \mathrm{H}, \mathrm{d}$, $J=11.4 \mathrm{~Hz}$, benzyl), $4.72(1 \mathrm{H}, \mathrm{d}, J=11.4 \mathrm{~Hz}$, benzyl), $7.30 \sim 7.42(5 \mathrm{H}, \mathrm{m}, \mathrm{Ph}) ;{ }^{13} \mathrm{C} \mathrm{NMR}\left(75 \mathrm{MHz}, \mathrm{CDCl}_{3}\right) \delta$ 61.0, 63.2, 71.9, 72.6, 79.4, 128.2, 128.4, 128.9, 137.8 .

\section{3-O-Benzyl-2,4-O-isopropylidene-D-threitol (10a)}

To a solution of triol $9 \mathrm{a}(2.17 \mathrm{~g}, 10.2 \mathrm{mmol})$ and pyridinium $p$-toluenesulfonate (PPTS, $251 \mathrm{mg}, 1.0 \mathrm{mmol}$ ) in DMF $(25 \mathrm{ml})$ was added dropwise 2-methoxypropene $(1.6 \mathrm{ml}$, $15.3 \mathrm{mmol})$ in DMF $(5 \mathrm{ml})$ at $-15^{\circ} \mathrm{C}$. After being stirred at $-15^{\circ} \mathrm{C}$ for 7 hour, the resulting mixture was neutralized with $\mathrm{Et}_{3} \mathrm{~N}$. The reaction mixture was diluted with EtOAc and washed with brine. The organic layer was dried and concentrated to afford the residue, which was purified by flash chromatography ( $100 \mathrm{~g}$ silica gel, $1: 3$ to $2: 1$ EtOAc/hexane as an eluent) to give 10a (700 $\mathrm{mg}, 27 \%)$ as white crystals and a mixture of 11a and 12a $(1.77 \mathrm{~g}, 68 \%)$ as a colorless syrup; 10a: m.p. $61 \sim 62^{\circ} \mathrm{C} ;[\alpha]_{\mathrm{D}}^{24}-65^{\circ}(c$ 1.55, $\mathrm{CHCl}_{3}$ ) \{lit. [8] for $\mathbf{1 0 b}$ (enantiomer of 10a): m.p. $\left.60 \sim 61^{\circ} \mathrm{C} ;[\alpha]_{\mathrm{D}}+64^{\circ}\left(c 0.3, \mathrm{CHCl}_{3}\right)\right\}$; IR $v_{\max }$ (neat) 3450 , 2990, 2940, 2875, 1455, 1385, 1200, 1120, 1080, 1055, $1025 \mathrm{~cm}^{-1}$; HR FAB-MS $\mathrm{m} / z$ for $\mathrm{C}_{14} \mathrm{H}_{21} \mathrm{O}_{4}(\mathrm{M}+\mathrm{H})^{+}$, Calcd: 253.1440 , Found: $253.1453 ;{ }^{1} \mathrm{H}$ NMR $(300 \mathrm{MHz}$, $\left.\mathrm{CDCl}_{3}\right) \delta: 1.46,1.47\left(3 \mathrm{H} \times 2,2 \mathrm{~s}, \mathrm{Me}_{2} \mathrm{C}<\right), 1.94 \sim 2.10(1 \mathrm{H}$, $\mathrm{m}, \mathrm{OH}), 3.25 \sim 3.35(1 \mathrm{H}, \mathrm{m}, \mathrm{H}-5), 3.62(1 \mathrm{H}, \mathrm{ddd}, J=4.5$, $J=8.7, J=11.4 \mathrm{~Hz}, \mathrm{H}-4), 3.80 \sim 3.88(1 \mathrm{H}, \mathrm{m}, \mathrm{H}-1 \mathrm{a}), 3.91$ $(1 \mathrm{H}, \mathrm{dd}, J=2.4, J=12.9 \mathrm{~Hz}, \mathrm{H}-6 \mathrm{a}), 3.95 \sim 4.03(1 \mathrm{H}, \mathrm{m}, \mathrm{H}-$ 1b), $4.04(1 \mathrm{H}, \mathrm{dd}, J=2.1, J=12.9 \mathrm{~Hz}, \mathrm{H}-6 \mathrm{~b}), 4.44(1 \mathrm{H}, \mathrm{d}$, $J=12.3 \mathrm{~Hz}$, benzyl), $4.76(1 \mathrm{H}, \mathrm{d}, J=12.3 \mathrm{~Hz}$, benzyl), 7.24 7.44 (5H, m, Ph); ${ }^{13} \mathrm{C}$ NMR $\left(75 \mathrm{MHz}, \mathrm{CDCl}_{3}\right) \delta$ : $19.1,28.9,61.1,62.9,69.9,70.7,71.6,98.8,127.9,128.0$, $128.5,137.8$. The isomeric compounds 11a and 12a could be converted into $9 \mathrm{a}$ by the following procedure and reused: The mixture of $11 \mathrm{a}$ and $12 \mathrm{a}(1.77 \mathrm{~g}, 7.02 \mathrm{mmol})$ was dissolved in $60 \%$ aq $\mathrm{AcOH}(13 \mathrm{ml})$ at room temperature. After stirring for 32 hour, the reaction mixture was concentrated to give a residue, which was recrystallized from benzene to afford triol 9a $(1.30 \mathrm{~g}, 87 \%)$ as white crystals.

\section{(4R,5R)-5-Benzyloxy-4-[8-(2-hexyl-[1,3]dioxolan-2-yl)- oct-1-enyl]-2,2-dimethyl-[1,3]dioxane (14a)}

To a solution of $(\mathrm{COCl})_{2}\left(2.0 \mathrm{~mol} /\right.$ liter in $\mathrm{CH}_{2} \mathrm{Cl}_{2}, 3.9 \mathrm{ml}$, $7.8 \mathrm{mmol})$ was added dropwise DMSO $(1.11 \mathrm{ml}$, $15.6 \mathrm{mmol})$ at $-78^{\circ} \mathrm{C}$ for 40 minutes under argon. To this 
mixture was added a solution of alcohol 10a $(657 \mathrm{mg}$, $2.60 \mathrm{mmol})$ in $\mathrm{CH}_{2} \mathrm{Cl}_{2}(16 \mathrm{ml})$ at $-78^{\circ} \mathrm{C}$. The reaction mixture was stirred at $-78^{\circ} \mathrm{C}$ for 40 minutes and then treated with $\mathrm{Et}_{3} \mathrm{~N}(3.26 \mathrm{ml}, 23.4 \mathrm{mmol})$. The resulting suspension was further stirred at $0^{\circ} \mathrm{C}$ for 30 minutes, and then diluted with $\mathrm{Et}_{2} \mathrm{O}$. The organic layer was washed with saturated $\mathrm{NH}_{4} \mathrm{Cl}$ aq solution and dried. Evaporation of the solvents gave crude aldehyde $(720.0 \mathrm{mg})$. To a solution of phosphonium salt 13 [10] $(6.22 \mathrm{~g}, 10.4 \mathrm{mmol})$ in dry THF $(19 \mathrm{ml})$ was added dropwise $n$-butyl lithium $(1.59 \mathrm{~mol} /$ liter in hexane, $8.50 \mathrm{ml}, 13.5 \mathrm{mmol}$ ) at $-78^{\circ} \mathrm{C}$ and the mixture was stirred for 15 minutes at room temperature. After cooling at $-78^{\circ} \mathrm{C}$, to the mixture was added a solution of the crude aldehyde $(720 \mathrm{mg})$ in THF $(9 \mathrm{ml})$ dropwise via a cannula. After stirring for 15 minutes, to the mixture was added $t$ - $\mathrm{BuOH}(1.2 \mathrm{ml})$ and then the dark red solution was warmed to room temperature. The resulting mixture was diluted with EtOAc, and washed with saturated $\mathrm{NH}_{4} \mathrm{Cl}$ aq and brine, and then dried. Removal of the solvent gave a residue, which was purified by flash chromatography $(70 \mathrm{~g}$ silica gel, EtOAc/toluene $=1 / 40$ to $1 / 15$ as an eluent) to give coupling product 14a $(574 \mathrm{mg}, 45 \%)$ as a mixtures of geometrical isomers $(E: Z=c a .1: 4)$; IR $v_{\max }$ (neat) 2930 , 2840, 1455, 1380, 1370, 1200, 1130, 1090, $1070 \mathrm{~cm}^{-1}$; Anal Found: C, 73.75; H, 9.87\%. Calcd for $\mathrm{C}_{30} \mathrm{H}_{48} \mathrm{O}_{5}$ : C, 73.73; H, 9.90\%; ${ }^{1} \mathrm{H} \mathrm{NMR}\left(300 \mathrm{MHz}, \mathrm{CDCl}_{3}\right) \delta: 0.88(3 \mathrm{H}$, $\left.\mathrm{t}, J=6.8 \mathrm{~Hz}, \mathrm{CH}_{2} \mathrm{C}_{3}\right), 1.47,1.49\left(3 \mathrm{H} \times 2,2 \mathrm{~s}, \mathrm{Me}_{2} \mathrm{C}<\right)$, $1.22 \sim 1.64\left(20 \mathrm{H}, \mathrm{m}, 10 \times-\mathrm{CH}_{2}-\right), 1.88 \sim 2.16(2 \mathrm{H}, \mathrm{m}$, $\left.\mathrm{C}=\mathrm{CHCH}_{2}-\right), \quad 3.17 \quad(1 \mathrm{H}, \quad \mathrm{m}, \quad \mathrm{H}-5), \quad 3.92 \quad(4 \mathrm{H}, \quad \mathrm{s}$, $\left.-\mathrm{O}\left(\mathrm{CH}_{2}\right)_{2} \mathrm{O}-\right), 3.94 \sim 4.01(2 \mathrm{H}, \mathrm{m}, \mathrm{H}-4, \mathrm{H}-6 \mathrm{a}), 4.57(1 \mathrm{H}, \mathrm{d}$ $J=12.5 \mathrm{~Hz}$, benzyl), $4.71(1 \mathrm{H}, \mathrm{d}, J=12.5 \mathrm{~Hz}$, benzyl), $4.68 \sim 4.78(1 \mathrm{H}, \mathrm{m}, \mathrm{H}-6 \mathrm{~b}), 5.54 \sim 5.82(2 \mathrm{H}, \mathrm{m},-\mathrm{CH}=\mathrm{CH}-)$, $7.24 \sim 7.44(5 \mathrm{H}, \mathrm{m}, \mathrm{Ph})$.

\section{$(4 R, 5 R)-4-[8-(2-H e x y l-[1,3]$ dioxolan-2-yl)-octyl]-2,2- dimethyl-[1,3]dioxan-5-ol (15a)}

A mixture of 14a (402 mg, $0.82 \mathrm{mmol})$ and $20 \% \mathrm{Pd}(\mathrm{OH})_{2}$ on activated carbon $(107 \mathrm{mg})$ in THF $(1.5 \mathrm{ml})$ was hydrogenated at room temperature under atmospheric pressure of $\mathrm{H}_{2}$ for 2 hour. After addition of $\mathrm{K}_{2} \mathrm{CO}_{3}(50 \mathrm{mg})$ to the mixture, the insoluble material was removed by filtration through celite (EtOAc as an eluent). The filtrate was concentrated to give a residue, which was purified by column chromatography ( $10 \mathrm{~g}$ silica gel, $1 / 8$ to $1 / 4$ EtOAc/hexane as an eluent) to afford alcohol 15a (289 mg, $88 \%)$ as a colorless syrup; $[\alpha]_{\mathrm{D}}^{22}-3.9^{\circ}\left(c 0.93, \mathrm{CHCl}_{3}\right)$; IR $v_{\max }$ (neat) 3460, 2930, 2855, 1460, 1380, 1200, $1080 \mathrm{~cm}^{-1}$; HR FAB-MS $\mathrm{m} / z$ for $\mathrm{C}_{23} \mathrm{H}_{45} \mathrm{O}_{5}(\mathrm{M}+\mathrm{H})^{+}$, Calcd: 401.3267, Found: 401.3266; Anal Found: C, 68.84; $\mathrm{H}, 10.92 \%$. Calcd for $\mathrm{C}_{23} \mathrm{H}_{44} \mathrm{O}_{5}: \mathrm{C}, 68,96 ; \mathrm{H}, 11.07 \% ;{ }^{1} \mathrm{H}$
NMR $\left(300 \mathrm{MHz}, \mathrm{CDCl}_{3}\right) \delta: 0.88(3 \mathrm{H}, \mathrm{t}, J=6.6 \mathrm{~Hz}$, $\left.\mathrm{CH}_{2} \underline{\mathrm{C}}_{3}\right), 1.20 \sim 1.63\left(26 \mathrm{H}, \mathrm{m}, 13 \times-\mathrm{CH}_{2}-\right), 1.42,1.46$ $\left(3 \mathrm{H} \times 2,2 \mathrm{~s}, \mathrm{Me}_{2} \mathrm{C}<\right), 2.53(1 \mathrm{H}, \mathrm{d},=11.7 \mathrm{~Hz}, \mathrm{OH}), 3.31$ $(1 \mathrm{H}, \mathrm{m}, \mathrm{H}-5), 3.76 \sim 3.88$ (2H, m, H-6a, H-4), $3.92(4 \mathrm{H}, \mathrm{s}$, $\left.-\mathrm{O}\left(\mathrm{CH}_{2}\right)_{2} \mathrm{O}-\right), 4.04(1 \mathrm{H}, \mathrm{dd}, J=1.2, J=12.3 \mathrm{~Hz}, \mathrm{H}-6 \mathrm{~b}) ;{ }^{13} \mathrm{C}$ NMR $\left(75 \mathrm{MHz}, \mathrm{CDCl}_{3}\right) \delta: 14.1,18.4,22.6,23.8,24.8$, $29.4,29.5,29.6,29.7,29.9,31.3,31.8,37.1,64.8,65.1$, $66.2,72.1,98.8,111.9$.

\section{(4R)-\{4-[8-(2-Hexyl-[1,3]dioxolan-2-yl)-octyl]-2,2- dimethyl-[1,3]dioxan-5-ylidene\}-acetic Acid Ethyl Ester (16a)}

To the mixture of alcohol 15a (413 mg, $1.03 \mathrm{mmol})$ and 4A molecular sieves $(330 \mathrm{mg})$ in dry $\mathrm{CH}_{2} \mathrm{Cl}_{2}(17 \mathrm{ml})$ was added a slurry of $\mathrm{NaOAc}(592 \mathrm{mg}, 7.21 \mathrm{mmol}), \mathrm{PCC}(778 \mathrm{mg}$, $3.61 \mathrm{mmol})$ and $4 \mathrm{~A}$ molecular sieves $(330 \mathrm{mg})$ in $\mathrm{CH}_{2} \mathrm{Cl}_{2}$ $(17 \mathrm{ml})$ at room temperature and the mixture was stirred at room temperature for 2 hour. The resulting precipitate was filtered off over celite and thoroughly washed with diethyl ether. The filtrate was concentrated to give a crude ketone $(470 \mathrm{mg})$, which was used in the next reaction without further purification. To a solution of the ketone $(470 \mathrm{mg})$ in toluene $(14.1 \mathrm{ml})$ was added $\mathrm{Ph}_{3} \mathrm{P}=\mathrm{CHCO}_{2} \mathrm{Et}(1.26 \mathrm{~g}$, $3.61 \mathrm{mmol}$ ) and the mixture was heated at $100^{\circ} \mathrm{C}$ for 14 hour. The resulting mixture was cooled and concentrated to give a residue, which was purified by flash chromatography (35 g silica gel, 1/25 to 1/15 EtOAc/hexane as an eluent) to afford unsaturated ester 16a (469 mg, 97\% for 2 steps) as a colorless syrup; $[\alpha]_{\mathrm{D}}^{18}+78^{\circ}\left(c 0.83, \mathrm{CHCl}_{3}\right)$; IR $v_{\max }$ (neat) 2980, 2930, 2855, 1715, 1650, 1460, 1380, 1370, 1210, $1150,1040 \mathrm{~cm}^{-1}$; EI-MS $\mathrm{m} / z 453\left(\mathrm{M}^{+}-\mathrm{Me}, 11 \%\right), 410$ (16), 383 (79), 325 (16) and 157 (100); HR EI-MS $m / z$ for $\mathrm{C}_{26} \mathrm{H}_{45} \mathrm{O}_{6}\left(\mathrm{M}^{+}-\mathrm{Me}\right)$, Calcd: 453.3216, Found: 453.3218; Anal Found: C, 69.05; H, 10.24\%. Calcd for $\mathrm{C}_{27} \mathrm{H}_{48} \mathrm{O}_{6}$ : C, 69.19; $\mathrm{H}, 10.32 \% ;{ }^{1} \mathrm{H}$ NMR $\left(300 \mathrm{MHz}, \mathrm{CDCl}_{3}\right) \delta: 0.88$ $\left(3 \mathrm{H}, \quad \mathrm{t}, \quad J=6.6 \mathrm{~Hz}, \quad \mathrm{CH}_{2} \mathrm{C}_{3}\right), \quad 1.22 \sim 1.82(29 \mathrm{H}, \mathrm{m}$, $\left.13 \times-\mathrm{CH}_{2}-, \mathrm{OCH}_{2} \mathrm{CH}_{3}\right), 1.38,1.39\left(3 \mathrm{H} \times 2,2 \mathrm{~s}, \mathrm{Me}_{2} \mathrm{C}<\right)$, $3.93\left(4 \mathrm{H}, \mathrm{s},-\mathrm{O}\left(\mathrm{CH}_{2}\right)_{2} \mathrm{O}-\right), 4.16(2 \mathrm{H}, \mathrm{q}, J=7.1 \mathrm{~Hz}$, $\left.\mathrm{OCH}_{2} \mathrm{CH}_{3}\right), 4.32(1 \mathrm{H}, \mathrm{m}, \mathrm{H}-4), 4.64(1 \mathrm{H}, \mathrm{ddd}, J=2.0$, $J=2.0, J=17.8 \mathrm{~Hz}, \mathrm{H}-6 \mathrm{a}), 5.02(1 \mathrm{H}, \mathrm{dd}, J=2.0, J=17.8 \mathrm{~Hz}$, $\mathrm{H}-6 \mathrm{~b}), 5.61(1 \mathrm{H}, \mathrm{dd}, J=2.0, J=2.0 \mathrm{~Hz},-\mathrm{C}=\mathrm{C} \underline{\mathrm{H}}-) ;{ }^{13} \mathrm{C}$ NMR $\left(75 \mathrm{MHz}, \mathrm{CDCl}_{3}\right) \delta: 14.1,14.2,22.6,23.8,24.3$, 25.1, 29.4, 29.4, 29.5, 29.6, 29.9, 31.4, 31.8, 37.1, 60.1, $61.9,64.9,69.6,100.4,110.8,111.9,162.6,166.0$.

\section{(4R)-2-\{4-[8-(2-Hexyl-[1,3]dioxolan-2-yl)-octyl]-2,2- dimethyl-[1,3]dioxan-5-ylidene\}-ethanol (17a)}

To a solution of ester 16a ( $374 \mathrm{mg}, 0.80 \mathrm{mmol})$ in toluene $(9.0 \mathrm{ml})$ was added dropwise DIBAL-H $(1.01 \mathrm{~mol} / \mathrm{liter}$ in 
toluene, $2.76 \mathrm{ml}, 2.79 \mathrm{mmol}$ ) at $-78^{\circ} \mathrm{C}$ under argon. After being stirred at $-78^{\circ} \mathrm{C}$ for 30 minutes, to the solution was added acetone $(2.5 \mathrm{ml})$ and stirring was further continued for 10 minutes at $0^{\circ} \mathrm{C}$. To the resulting mixture was added excess $\mathrm{Na}_{2} \mathrm{SO}_{4} \cdot 10 \mathrm{H}_{2} \mathrm{O}$ and the mixture was stirred for 1 hour. The insoluble material was removed by filtration through celite, and the filtrate was concentrated to give a residue, which was purified by column chromatography ( $20 \mathrm{~g}$ silica gel, $1 / 7$ to $1 / 3 \mathrm{EtOAc/hexane}$ as an eluent) to afford allylic alcohol $\mathbf{1 7 a}(322 \mathrm{mg}, 95 \%)$ as a colorless syrup; $[\alpha]_{\mathrm{D}}^{21}+68^{\circ}\left(c \quad 1.10, \mathrm{CHCl}_{3}\right) ;$ IR $v_{\max }$ (neat) $3380 \sim 3500,2985,2930,2850,1455,1380,1370,1225$, $1160,1080 \mathrm{~cm}^{-1}$; EI-MS $\mathrm{m} / \mathrm{z} 425\left(\mathrm{M}^{+}-\mathrm{H}, 1.1 \%\right), 411$ $\left(\mathrm{M}^{+}-\mathrm{Me}, 16\right), 355$ (13), 341 (34), 281 (30) and 157 (100); HR EI-MS $m / z$ for $\mathrm{C}_{25} \mathrm{H}_{45} \mathrm{O}_{5}\left(\mathrm{M}^{+}-\mathrm{H}\right)$, Calcd: 425.3267, Found: $425.3264 ;{ }^{1} \mathrm{H}$ NMR $\left(300 \mathrm{MHz}, \mathrm{CDCl}_{3}\right) \delta: 0.88(3 \mathrm{H}$, $\left.\mathrm{t}, J=6.6 \mathrm{~Hz}, \mathrm{CH}_{2} \mathrm{CH}_{3}\right), 1.22 \sim 1.82\left(27 \mathrm{H}, \mathrm{m}, 13 \times-\mathrm{CH}_{2}-\right.$, $\mathrm{OH}), \quad 1.37,1.41\left(3 \mathrm{H} \times 2,2 \mathrm{~s}, \mathrm{Me}_{2} \mathrm{C}<\right), 3.92(4 \mathrm{H}, \mathrm{s}$, $\left.-\mathrm{O}\left(\mathrm{CH}_{2}\right)_{2} \mathrm{O}-\right), 4.12$ (2H, m, H-4, H-6a), 4.22 4.42 (3H, m, $\left.\mathrm{H}-6 \mathrm{~b},-\mathrm{C}_{2} \mathrm{OH}\right), 5.42(1 \mathrm{H}, \mathrm{dt}, J=1.7, J=6.6 \mathrm{~Hz},-\mathrm{C}=\mathrm{C} \underline{\mathrm{H}}-)$; ${ }^{13} \mathrm{C}$ NMR $\left(75 \mathrm{MHz}, \mathrm{CDCl}_{3}\right) \delta: 14.1,22.6,23.1,23.8,23.8$, 25.2, 25.8, 25.9, 29.4, 29.5, 29.5, 29.6, 29.9, 31.8, 32.0, $37.1,58.1,59.4,64.8,70.1,99.8,111.9,119.6,141.2$.

\section{(4R,5S)-2,2,2-Trichloro- $N$ - $\{4$-[8-(2-hexyl-[1,3]dioxolan- 2-yl)-octyl]-2,2-dimethyl-5-vinyl-[1,3]dioxan-5-yl\}- acetamide 19a and Its $(4 R, 5 R)$ Isomer 20a}

To a solution of allylic alcohol $\mathbf{1 7 a}(508 \mathrm{mg}, 1.19 \mathrm{mmol})$ in $\mathrm{CH}_{2} \mathrm{Cl}_{2}(15 \mathrm{ml})$ were added trichloroacetonitrile $(0.30 \mathrm{ml}$, $2.98 \mathrm{mmol})$ and $\mathrm{DBU}(34.8 \mu \mathrm{l}, 0.233 \mathrm{mmol})$ at $0^{\circ} \mathrm{C}$, and the mixture was stirred at $0^{\circ} \mathrm{C}$ for 2 hour. The resulting mixture was concentrated to give a residue, which was passed through a short column of silica gel $(6 \mathrm{~g}, 1 / 10$ EtOAc/hexane containing $1 \% \mathrm{Et}_{3} \mathrm{~N}$ as an eluent) to afford roughly purified imidate $18 \mathbf{a}(651 \mathrm{mg})$ as a yellow syrup. To a solution of crude $18 \mathbf{a}(651 \mathrm{mg})$ in $o$-xylene $(65 \mathrm{ml})$ was added $\mathrm{K}_{2} \mathrm{CO}_{3}(130 \mathrm{mg})$, and the mixture was heated at $140^{\circ} \mathrm{C}$ in a sealed tube for 89 hour under argon. The resulting mixture was concentrated to give a residue, which was purified by column chromatography ( $57 \mathrm{~g}$ silica gel, $1 / 150$ EtOAc/toluene as an eluent) to afford first, rearranged products 19a (336 $\mathrm{mg}, 49 \%)$ as a colorless syrup; $[\alpha]_{\mathrm{D}}^{20}+21^{\circ}\left(c 0.22, \mathrm{CHCl}_{3}\right)$; IR $v_{\max }$ (neat) 3430 , 2930, 2860, 1725, 1505, 1460, 1380, 1200, $1100 \mathrm{~cm}^{-1}$; HR FAB-MS $m / z$ for $\mathrm{C}_{27} \mathrm{H}_{47} \mathrm{C}_{13} \mathrm{NO}_{5}(\mathrm{M}+\mathrm{H})^{+}$, Calcd: 570.2520, Found: $570.2534 ;{ }^{1} \mathrm{H}$ NMR $\left(300 \mathrm{MHz}, \mathrm{CDCl}_{3}\right) \delta: 0.87(3 \mathrm{H}$, $\left.\mathrm{t}, J=6.6 \mathrm{~Hz}, \mathrm{CH}_{2} \mathrm{C}_{3}\right), 1.20 \sim 1.62\left(26 \mathrm{H}, \mathrm{m}, 13 \times-\mathrm{CH}_{2}-\right)$, $1.43,1.58\left(3 \mathrm{H} \times 2,2 \mathrm{~s}, \mathrm{Me}_{2} \mathrm{C}<\right), 3.76(1 \mathrm{H}, \mathrm{d}, J=11.1 \mathrm{~Hz}, \mathrm{H}-$ 6a), $3.91\left(4 \mathrm{H}, \mathrm{s},-\mathrm{O}\left(\mathrm{CH}_{2}\right)_{2} \mathrm{O}-\right), 4.57(1 \mathrm{H}, \mathrm{dd}, J=6.3$, $J=8.7 \mathrm{~Hz}, \mathrm{H}-4), 4.61(1 \mathrm{H}, \mathrm{d}, J=11.1 \mathrm{~Hz}, \mathrm{H}-6 \mathrm{~b}), 5.23(1 \mathrm{H}$, d, $J=17.7 \mathrm{~Hz},-\mathrm{CH}=\mathrm{C} \underline{\mathrm{H}} \mathrm{H}), 5.40(1 \mathrm{H}, \mathrm{d}, J=11.1 \mathrm{~Hz}$, $-\mathrm{CH}=\mathrm{CH} \underline{\mathrm{H}}), \quad 6.44 \quad(1 \mathrm{H}, \quad \mathrm{dd}, \quad J=11.1, \quad J=17.7 \mathrm{~Hz}$, $\left.-\mathrm{C} \underline{\mathrm{H}}=\mathrm{CH}_{2}\right), 6.46(1 \mathrm{H}, \mathrm{s}, \mathrm{NH}) ;{ }^{13} \mathrm{C} \mathrm{NMR}\left(75 \mathrm{MHz}, \mathrm{CDCl}_{3}\right)$ $\delta: 14.1,19.4,22.6,23.8,25.5,28.7,29.4,29.4,29.5,29.6$, $29.9,31.8,37.1,57.9,64.9,65.3,70.7,92.8,99.5,111.9$, $114.5,135.8,160.8$.

Further elution (1/50 EtOAc/toluene as an eluent) gave isomeric product 20a (306 $\mathrm{mg}, 45 \%)$ as a colorless syrup; $[\alpha]_{\mathrm{D}}^{21}-19^{\circ}\left(c 1.09, \mathrm{CHCl}_{3}\right)$; IR $v_{\max }$ (neat) 3405, 2930, 2850, 1730, 1505, 1385, 1370, 1200, 1110, 1080, $1055 \mathrm{~cm}^{-1}$; HR FAB-MS $m / z$ for $\mathrm{C}_{27} \mathrm{H}_{47} \mathrm{Cl}_{3} \mathrm{NO}_{5}(\mathrm{M}+\mathrm{H})^{+}$, Calcd: 570.2520, Found: 570.2531; ${ }^{1} \mathrm{H}$ NMR $\left(300 \mathrm{MHz}, \mathrm{CDCl}_{3}\right.$ ) $\delta: 0.88\left(3 \mathrm{H}, \mathrm{t}, J=6.6 \mathrm{~Hz}, \mathrm{CH}_{2} \mathrm{C}_{3}\right), 1.15 \sim 1.65(26 \mathrm{H}, \mathrm{m}$, $\left.13 \times-\mathrm{CH}_{2}-\right), 1.42,1.48\left(3 \mathrm{H} \times 2,2 \mathrm{~s}, \mathrm{Me}_{2} \mathrm{C}<\right), 3.78(1 \mathrm{H}, \mathrm{dd}$, $J=1.5, \quad J=9.3 \mathrm{~Hz}, \quad \mathrm{H}-4), \quad 3.86 \quad(1 \mathrm{H}, \quad \mathrm{d}, \quad J=12.0 \mathrm{~Hz}$, H-6a), $3.92\left(4 \mathrm{H}, \mathrm{s},-\mathrm{O}\left(\mathrm{CH}_{2}\right)_{2} \mathrm{O}-\right), 4.20(1 \mathrm{H}, \mathrm{d}, J=12.0 \mathrm{~Hz}$, $\mathrm{H}-6 \mathrm{~b}), \quad 5.15(1 \mathrm{H}, \quad \mathrm{d}, \quad J=18.0 \mathrm{~Hz}, \quad-\mathrm{CH}=\mathrm{C} \underline{\mathrm{H}}), \quad 5.32$ $(1 \mathrm{H}, \mathrm{d}, J=11.4 \mathrm{~Hz},-\mathrm{CH}=\mathrm{CH} \underline{\mathrm{H}}), 5.89(1 \mathrm{H}, \mathrm{dd}, J=11.4$, $\left.J=18.0 \mathrm{~Hz},-\mathrm{C} \underline{\mathrm{H}}=\mathrm{CH}_{2}\right), 7.15(1 \mathrm{H}, \mathrm{s}, \mathrm{NH}) ;{ }^{13} \mathrm{C} \mathrm{NMR}$ $\left(75 \mathrm{MHz}, \mathrm{CDCl}_{3}\right) \delta: 14.1,18.4,22.6,23.8,25.8,28.6,29.2$, 29.4, 29.4, 29.5, 29.6, 29.9, 31.8, 37.1, 58.3, 64.3, 64.9, 76.0, 93.2, 99.3, 111.9, 116.6, 134.0, 161.2. Optical purities of 20a was confirmed to be $>99 \%$ ee (determined by HPLC [DAICEL CHIRALCEL OD, $4.6 \mathrm{~mm}$ ID, $250 \mathrm{mml}$, $i-\mathrm{PrOH} /$ hexane $=1 / 50$, flow rate $=1.5 \mathrm{ml} /$ minute, retention volume for 20a: $7.3 \mathrm{ml}, 20 \mathrm{~b}: 6.1 \mathrm{ml}]$ ).

\section{$(4 R, 5 S)-\{4-[8-(2-H e x y l-[1,3]$ dioxolan-2-yl)-octyl]-2,2- dimethyl-5-vinyl-[1,3]dioxan-5-yl\}-carbamic Acid Benzyl Ester (21a)}

To a solution of 19a $(67 \mathrm{mg}, 0.117 \mathrm{mmol})$ in toluene $(2.0 \mathrm{ml})$ was added dropwise DIBAL-H $(1.01 \mathrm{~mol} / \mathrm{liter}$ in toluene, $0.23 \mathrm{ml}, 0.23 \mathrm{mmol}$ ) at $-78^{\circ} \mathrm{C}$ under argon. After being stirred at $-78^{\circ} \mathrm{C}$ for 10 minutes, to the solution was added acetone $(0.5 \mathrm{ml})$ and the mixture was stirred for 10 minutes at $0^{\circ} \mathrm{C}$. To the resulting mixture was added excess $\mathrm{Na}_{2} \mathrm{SO}_{4} \cdot 10 \mathrm{H}_{2} \mathrm{O}$ and the mixture was further stirred at $0^{\circ} \mathrm{C}$ for 1.5 hour. The insoluble material was removed by filtration through celite (EtOAc as an eluent) and the filtrate was concentrated to afford crude amine $(62.3 \mathrm{mg})$. To a solution of the crude amine $(62.3 \mathrm{mg})$ in 1,4-dioxane $(2 \mathrm{ml})$ were added $\mathrm{NaHCO}_{3}(79 \mathrm{mg}, 0.94 \mathrm{mmol})$ and carbobenzoxy chloride $(\mathrm{CbzCl}, 0.13 \mathrm{ml}, 0.94 \mathrm{mmol})$ at room temperature and the mixture was stirred for 8 hour. The resulting mixture was diluted with EtOAc and washed with brine, and dried. Removal of the solvent gave a residue, which was purified by chromatography $(5 \mathrm{~g}$ silica gel, $1 / 20$ to $1 / 10$, EtOAc/hexane as an eluent) to give carbamate 21a (66 mg, quant.) as a colorless syrup; $[\alpha]_{\mathrm{D}}^{22}$ $+16^{\circ}\left(c \quad 1.12, \mathrm{CHCl}_{3}\right)$; IR $v_{\max }$ (neat) $3350,2930,2855$, 
$1725,1505,1455,1380,1260,1235,1200,1080$, $1060 \mathrm{~cm}^{-1}$; HR FAB-MS $\mathrm{m} / z$ for $\mathrm{C}_{33} \mathrm{H}_{54} \mathrm{NO}_{6}(\mathrm{M}+\mathrm{H})^{+}$, Calcd: 560.3951, Found: 560.3961; Anal Found: C, 70.80; $\mathrm{H}, 9.50 ; \mathrm{N}, 2.46 \%$. Calcd for $\mathrm{C}_{33} \mathrm{H}_{53} \mathrm{NO}_{6}: \mathrm{C}, 70.81 ; \mathrm{H}$, 9.54; N, 2.50\%; ${ }^{1} \mathrm{H}$ NMR $\left(300 \mathrm{MHz}, \mathrm{CDCl}_{3}\right) \delta: 0.88(3 \mathrm{H}, \mathrm{t}$, $\left.J=6.6 \mathrm{~Hz}, \mathrm{CH}_{2} \mathrm{C}_{3}\right), 1.18 \sim 1.62\left(26 \mathrm{H}, \mathrm{m}, 13 \times-\mathrm{CH}_{2}-\right)$, $1.42,1.56\left(3 \mathrm{H} \times 2,2 \mathrm{~s}, \mathrm{Me}_{2} \mathrm{C}<\right), 3.80(1 \mathrm{H}, \mathrm{d}, J=11.4 \mathrm{~Hz}$, $\mathrm{H}-6 \mathrm{a}), 3.92\left(4 \mathrm{H}, \mathrm{s},-\mathrm{O}\left(\mathrm{CH}_{2}\right)_{2} \mathrm{O}-\right), 4.38(1 \mathrm{H}, \mathrm{bs}, \mathrm{H}-4), 4.49$ $(1 \mathrm{H}, \mathrm{d}, J=11.4 \mathrm{~Hz}, \mathrm{H}-6 \mathrm{~b}), 4.74(1 \mathrm{H}, \mathrm{s}, \mathrm{NH}), 5.07(2 \mathrm{H}, \mathrm{s}$, $\left.-\mathrm{NHCO}_{2} \underline{\mathrm{H}}_{2} \mathrm{Ph}\right), 5.18(1 \mathrm{H}, \mathrm{d}, J=18.0 \mathrm{~Hz},-\mathrm{CH}=\mathrm{C} \underline{\mathrm{HH}})$, $5.30(1 \mathrm{H}, \mathrm{d}, J=11.1 \mathrm{~Hz},-\mathrm{CH}=\mathrm{CH} \underline{\mathrm{H}}), 6.33(1 \mathrm{H}, \mathrm{dd}$, $\left.J=11.1, J=18.0 \mathrm{~Hz},-\mathrm{C} \underline{\mathrm{H}}=\mathrm{CH}_{2}\right), 7.32 \sim 7.38(5 \mathrm{H}, \mathrm{m}, \mathrm{Ph})$; ${ }^{13} \mathrm{C}$ NMR $\left(75 \mathrm{MHz}, \mathrm{CDCl}_{3}\right) \delta: 14.1,19.4,22.6,23.8,23.8$, 25.8, 28.9, 29.3, 29.4, 29.5, 29.5, 29.6, 29.9, 31.8, 37.1, $55.9,64.8,66.5,66.7,72.0,99.1,111.9,114.1,128.2$, 128.3, 128.6, 136.1, 136.6, 154.6 .

\section{$(4 R, 5 R)-\{4-[8-(2-H e x y l-[1,3]$ dioxolan-2-yl)-octyl]-2,2- dimethyl-5-vinyl-[1,3]dioxan-5-yl\}-carbamic Acid Benzyl Ester (22a)}

By the same reaction conditions as described for the preparation of 21a from 19a, compound 20a (60 mg, $0.10 \mathrm{mmol})$ was converted to carbamate $22 \mathrm{a}(57 \mathrm{mg}, 97 \%$ for 2 steps); colorless syrup; $[\alpha]_{\mathrm{D}}^{24}-25^{\circ}\left(c 0.94, \mathrm{CHCl}_{3}\right)$; IR $v_{\max }$ (neat) $3430,2930,2855,1730,1505,1495,1455$, 1380, 1260, 1235, 1200, 1100, $1070 \mathrm{~cm}^{-1}$; HR FAB-MS $m / z$ for $\mathrm{C}_{33} \mathrm{H}_{54} \mathrm{NO}_{6}(\mathrm{M}+\mathrm{H})^{+}$, Calcd: 560.3951, Found: 560.3939; Anal Found: C, 70.85; H, 9.50; N, 2.47\%. Calcd for $\mathrm{C}_{33} \mathrm{H}_{53} \mathrm{NO}_{6}$ : C, 70.81; H, 9.54; N, 2.50\%; ${ }^{1} \mathrm{H}$ NMR $\left(300 \mathrm{MHz}, \mathrm{CDCl}_{3}\right) \delta: 0.88\left(3 \mathrm{H}, \mathrm{t}, J=6.6 \mathrm{~Hz}, \mathrm{CH}_{2} \mathrm{CH}_{3}\right)$, $1.15 \sim 1.64\left(26 \mathrm{H}, \mathrm{m}, 13 \times-\mathrm{CH}_{2}-\right), 1.41,1.46(3 \mathrm{H} \times 2$, $\left.2 \mathrm{~s}, \mathrm{Me}_{2} \mathrm{C}<\right), 3.69(1 \mathrm{H}, \mathrm{dd}, J=1.8, J=9.6 \mathrm{~Hz}, \mathrm{H}-4), 3.84$ $(1 \mathrm{H}, \mathrm{d}, J=11.7 \mathrm{~Hz}, \mathrm{H}-6 \mathrm{a}), 3.92\left(4 \mathrm{H}, \mathrm{s},-\mathrm{O}\left(\mathrm{CH}_{2}\right)_{2} \mathrm{O}-\right)$, $4.17(1 \mathrm{H}, \quad \mathrm{d}, \quad J=11.7 \mathrm{~Hz}, \quad \mathrm{H}-6 \mathrm{~b}), \quad 5.04(1 \mathrm{H}, \quad \mathrm{d}$, $\left.J=12.3 \mathrm{~Hz},-\mathrm{NHCO}_{2} \mathrm{C} \underline{\mathrm{HHPh}}\right), 5.12(1 \mathrm{H}, \mathrm{d}, J=12.3 \mathrm{~Hz}$, $\left.-\mathrm{NHCO}_{2} \mathrm{CH} \underline{\mathrm{HPh}}\right), 5.11(1 \mathrm{H}, \mathrm{d}, J=18.0 \mathrm{~Hz},-\mathrm{CH}=\mathrm{C} \underline{\mathrm{H}})$, $5.25(1 \mathrm{H}, \mathrm{d}, J=11.4 \mathrm{~Hz},-\mathrm{CH}=\mathrm{CH} \underline{\mathrm{H}}), 5.35(1 \mathrm{H}, \mathrm{s}, \mathrm{NH})$, $5.92\left(1 \mathrm{H}, \mathrm{dd}, J=11.4, J=18.0 \mathrm{~Hz},-\mathrm{C} \underline{\mathrm{H}}=\mathrm{CH}_{2}\right), 7.30 \sim 7.40$ $(5 \mathrm{H}, \mathrm{m}, \mathrm{Ph}) ;{ }^{13} \mathrm{C}$ NMR $\left(75 \mathrm{MHz}, \mathrm{CDCl}_{3}\right) \delta: 14.1,18.6$, 22.6, 23.8, 25.9, 28.4, 29.2, 29.4, 29.5, 29.6, 29.9, 31.8, $37.1,56.5,64.8,65.1,66.5,76.3,99.0,111.9,115.5,128.0$, 128.1, 128.5, 136.5, 136.9, 155.6 .

\section{(2S,3R)-2-Benzyloxycarbonylamino-3-hydroxy-2- hydroxymethyl-12-oxo-octadecanoic Acid Benzyl Ester (23a)}

Ozone was introduced into a solution of carbamate 21a $(19 \mathrm{mg}, 0.034 \mathrm{mmol})$ in $\mathrm{EtOH}(2 \mathrm{ml})$ at $-78^{\circ} \mathrm{C}$ for 10 minutes. After purging of excess ozone with a stream of $\mathrm{Ar}$ gas, to the solution was added $\mathrm{Me}_{2} \mathrm{~S}(25 \mu 1,0.34 \mathrm{mmol})$ and the mixture was stirred at $-78^{\circ} \mathrm{C}$ for 1 hour. The resulting mixture was diluted with EtOAc and washed with brine, and dried. Removal of the solvent gave crude aldehyde $(20 \mathrm{mg})$ as a pale yellow syrup. To a solution of the crude aldehyde in $t$ - $\mathrm{BuOH}(0.7 \mathrm{ml})$ and water $(0.7 \mathrm{ml})$ were added $\mathrm{NaH}_{2} \mathrm{PO}_{4} \cdot 2 \mathrm{H}_{2} \mathrm{O}(10.6 \mathrm{mg}, 0.068 \mathrm{mmol}), \mathrm{HOSO}_{2} \mathrm{NH}_{2}$ $(9.7 \mathrm{mg}, 0.1 \mathrm{mmol})$ and $\mathrm{NaClO}_{2}(9.0 \mathrm{mg}, 0.1 \mathrm{mmol})$ at room temperature. After stirring for 16 hour at room temperature, the reaction mixture was quenched with $20 \mathrm{wt} \%$ aq solution of $\mathrm{Na}_{2} \mathrm{~S}_{2} \mathrm{O}_{3}$. The aq phase was extracted with $\mathrm{CHCl}_{3}(\times 6)$. The combined organic layer was washed with $20 \%$ aq solution of $\mathrm{Na}_{2} \mathrm{~S}_{2} \mathrm{O}_{3}$, and dried. Evaporation of the solvent afforded crude carboxylic acid $(22 \mathrm{mg})$ as a white solid. To a solution of the crude carboxylic acid $(22 \mathrm{mg})$ in $\mathrm{CH}_{2} \mathrm{Cl}_{2}$ (1 ml) were added WSCD (13 mg, $0.068 \mathrm{mmol}$ ), DMAP $(2 \mathrm{mg}, 0.017 \mathrm{mmol})$ and benzyl alcohol $(7.0 \mu 1$, $0.068 \mathrm{mmol})$ at $0^{\circ} \mathrm{C}$. After being stirred at room temperature for 60 hour, the mixture was diluted with EtOAc and washed with brine and dried. Removal of the solvent gave a residue, which was purified by chromatography (1.2 g silica gel, 1/30 EtOAc/toluene as an eluent) to afford a benzyl ester $(15 \mathrm{mg})$ as a colorless syrup; IR $v_{\max }$ (neat) $3340,2920,2855,1730,1715,1500,1455$, $1255,1225,1080,1050,1030 \mathrm{~cm}^{-1}$; ${ }^{1} \mathrm{H}$ NMR $(300 \mathrm{MHz}$, $\left.\mathrm{CDCl}_{3}\right) \delta: 0.88\left(3 \mathrm{H}, \mathrm{t}, J=6.6 \mathrm{~Hz}, \mathrm{CH}_{2} \mathrm{CH}_{3}\right), 1.10 \sim 1.68$ $\left(26 \mathrm{H}, \mathrm{m}, 13 \times-\mathrm{CH}_{2}-\right), 1.41,1.59\left(3 \mathrm{H} \times 2,2 \mathrm{~s}, \mathrm{Me}_{2} \mathrm{C}<\right)$, $3.92\left(4 \mathrm{H}, \mathrm{s},-\mathrm{O}\left(\mathrm{CH}_{2}\right)_{2} \mathrm{O}-\right), 4.12(1 \mathrm{H}, \mathrm{bs}, \mathrm{H}-4), 4.21(1 \mathrm{H}, \mathrm{d}$, $J=15.0 \mathrm{~Hz}, \mathrm{H}-6 \mathrm{a}), 4.40(1 \mathrm{H}, \mathrm{d}, J=15.0 \mathrm{~Hz}, \mathrm{H}-6 \mathrm{~b}), 5.07$ $\left(2 \mathrm{H}, \mathrm{s},-\mathrm{NHCO}_{2} \underline{\mathrm{H}}_{2} \mathrm{Ph}\right), 5.24\left(2 \mathrm{H}, \mathrm{s},-\mathrm{CCO}_{2} \underline{\mathrm{C}}_{2} \mathrm{Ph}\right), 5.47$ $(1 \mathrm{H}, \mathrm{s}, \mathrm{NH}), 7.28 \sim 7.44(10 \mathrm{H}, \mathrm{m}, \mathrm{Ph})$. To the benzyl ester $(15 \mathrm{mg}, 0.034 \mathrm{mmol}$ ) was added $60 \%$ aq $\mathrm{AcOH}$ solution, and the mixture was heated at $50{ }^{\circ} \mathrm{C}$ for 19 hour. The mixture was concentrated and residual acetic acid was azeotropically removed with EtOH to afford a yellow syrup, which was purified by column chromatography ( $0.7 \mathrm{~g}$ silica gel, $1 / 5$ to $1 / 2 \mathrm{EtOAc/hexane}$ as an eluent) to give diol 23a ( $10 \mathrm{mg}, 50 \%$ for 4 steps) as colorless syrup; $[\alpha]_{\mathrm{D}}^{23}+4.9^{\circ}\left(c 1.41, \mathrm{CHCl}_{3}\right)$; IR $v_{\max }$ (neat) 3400, 2930, $2855,1740,1710,1510,1500,1455,1260,1215,1060$, $1030 \mathrm{~cm}^{-1}$; HR FAB-MS $\mathrm{m} / \mathrm{z}$ for $\mathrm{C}_{34} \mathrm{H}_{50} \mathrm{NO}_{7}(\mathrm{M}+\mathrm{H})^{+}$, Calcd: 584.3587, Found: 584.3581; Anal. Found: C, 69.96; $\mathrm{H}, 8.46 ; \mathrm{N}, 2.32 \%$. Calcd for $\mathrm{C}_{34} \mathrm{H}_{49} \mathrm{NO}_{7}: \mathrm{C}, 69.95 ; \mathrm{H}$, 8.46 ; N, 2.40\%; ${ }^{1} \mathrm{H}$ NMR $\left(300 \mathrm{MHz}, \mathrm{CDCl}_{3}\right) \delta: 0.88(3 \mathrm{H}, \mathrm{t}$, $\left.J=6.6 \mathrm{~Hz}, \mathrm{CH}_{2} \mathrm{CH}_{3}\right), 1.14 \sim 1.64\left(22 \mathrm{H}, \mathrm{m}, 11 \times-\mathrm{CH}_{2}-\right)$, $2.37(2 \mathrm{H} \times 2,2 \mathrm{t}, J=6.9 \mathrm{~Hz}, \mathrm{H}-11, \mathrm{H}-13), 3.00(1 \mathrm{H}, \mathrm{bs}, \mathrm{OH})$, $3.63(1 \mathrm{H}, \mathrm{bs}, \mathrm{OH}), 3.92 \sim 4.10\left(3 \mathrm{H}, \mathrm{m},-\mathrm{CH}_{2} \mathrm{OH}, \mathrm{H}-3\right), 5.10$ $\left(2 \mathrm{H}, \mathrm{s},-\mathrm{NHCO}_{2} \mathrm{CH}_{2} \mathrm{Ph}\right), 5.22\left(2 \mathrm{H}, \mathrm{bs},-\mathrm{CCO}_{2} \mathrm{CH}_{2} \mathrm{Ph}\right), 5.88$ $(1 \mathrm{H}, \mathrm{s}, \mathrm{NH}), 7.34(10 \mathrm{H}, \mathrm{bs}, \mathrm{Ph}) ;{ }^{13} \mathrm{C}$ NMR $(75 \mathrm{MHz}$, $\left.\mathrm{CDCl}_{3}\right) \delta: 14.0,22.5,23.8,23.8,25.9,28.9,29.1,29.2$, $31.5,31.6,42.7,42.8,64.2,67.3,67.6,69.0,74.0,128.1$, 
$128.2,128.3,128.4,128.6,135.4,135.9,157.1,170.9$, 211.9 .

(2S,3R)-2-Benzyloxycarbonylamino-2benzyloxymethoxymethyl-3-hydroxy-12-oxooctadecanoic Acid Benzyl Ester (24a)

To a solution of 23a (50 mg, $0.086 \mathrm{mmol})$ in $\mathrm{CH}_{2} \mathrm{Cl}_{2}$ were added $i$ - $\mathrm{Pr}_{2} \mathrm{NEt}(37.2 \mu \mathrm{l}, 0.214 \mathrm{mmol})$ and $\mathrm{BOM}-\mathrm{Cl}$ $(59.2 \mu \mathrm{l}, 0.427 \mathrm{mmol})$ at $0^{\circ} \mathrm{C}$. After stirring at $35^{\circ} \mathrm{C}$ for 23 hour, the resulting mixture was diluted with $\mathrm{CHCl}_{3}$ and washed with brine, and the organic layer was dried. Removal of the solvent gave a residue, which was purified by flash chromatography ( $8 \mathrm{~g}$ silica gel, $1 / 10$ to $1 / 6$ EtOAc/hexane as an eluent) to afford BOM ether 24a $(39 \mathrm{mg}, 64 \%)$ as a colorless syrup; $[\alpha]_{\mathrm{D}}^{24}+35^{\circ}(c 0.90$, $\mathrm{CHCl}_{3}$ ); IR $v_{\max }$ (neat) 3400, 2930, 2855, 1740, 1710, 1500, 1455, 1250,1220, 1040, $1030 \mathrm{~cm}^{-1}$; HR FAB-MS $m / z$ for $\mathrm{C}_{42} \mathrm{H}_{58} \mathrm{NO}_{8}(\mathrm{M}+\mathrm{H})^{+}$, Calcd: 704.4162, Found: 704.4182; ${ }^{1} \mathrm{H}$ NMR $\left(300 \mathrm{MHz}, \mathrm{CDCl}_{3}\right) \delta: 0.88(3 \mathrm{H}, \mathrm{t}$, $\left.J=6.3 \mathrm{~Hz}, \mathrm{CH}_{2} \mathrm{CH}_{3}\right), 1.10 \sim 1.65\left(22 \mathrm{H}, \mathrm{m}, 11 \times-\mathrm{CH}_{2}-\right)$, $2.38(4 \mathrm{H}, \mathrm{t}, J=7.1 \mathrm{~Hz}, \mathrm{H}-11, \mathrm{H}-13), 3.72 \sim 3.80(2 \mathrm{H}$, $\mathrm{m}, \quad-$ СЕнОВОМ, $\mathrm{H}-3), \quad 4.17(1 \mathrm{H}, \quad \mathrm{d}, \quad J=9.8 \mathrm{~Hz}$, -CḦBOM), $4.28(1 \mathrm{H}, \mathrm{d}, J=12.4 \mathrm{~Hz}, \mathrm{OH}), 4.41(1 \mathrm{H}, \mathrm{d}$, $\left.J=11.7 \mathrm{~Hz},-\mathrm{C}^{\mathrm{HHOCH}} \mathrm{Ph}_{2}\right), 4.47(1 \mathrm{H}, \mathrm{d}, J=11.7 \mathrm{~Hz}$, $\left.-\mathrm{CH}_{\mathbf{H O C H}} \mathrm{Ph}\right), 4.63\left(1 \mathrm{H}, \mathrm{d}, J=6.8 \mathrm{~Hz},-\mathrm{CH}_{2} \mathrm{OC} \underline{\mathrm{H} H \mathrm{Ph}}\right)$, $4.67\left(1 \mathrm{H}, \quad\right.$ d, $\left.J=6.8 \mathrm{~Hz},-\mathrm{CH}_{2} \mathrm{OCH} \underline{\mathrm{HPh}}\right), 5.08(1 \mathrm{H}$, d, $\left.J=11.9 \mathrm{~Hz},-\mathrm{NHCO}_{2} \mathrm{C} \underline{H} H \mathrm{Ph}\right), 5.13(1 \mathrm{H}, \quad \mathrm{d}, J=$ $\left.11.9 \mathrm{~Hz},-\mathrm{NHCO}_{2} \mathrm{CH} \underline{\mathrm{HPh}}\right), 5.16(1 \mathrm{H}, \mathrm{d}, J=12.4 \mathrm{~Hz}$, $\left.-\mathrm{CCO}_{2} \mathrm{C} \underline{H} H \mathrm{Ph}\right), 5.29\left(1 \mathrm{H}, \mathrm{d}, J=12.4 \mathrm{~Hz},-\mathrm{CCO}_{2} \mathrm{CH} \underline{H P h}\right)$, $5.85(1 \mathrm{H}, \mathrm{s}, \mathrm{NH}), 7.22 \sim 7.38(15 \mathrm{H}, \mathrm{m}, \mathrm{Ph}) ;{ }^{13} \mathrm{C} \mathrm{NMR}$ $\left(75 \mathrm{MHz}, \mathrm{CDCl}_{3}\right) \delta: 14.2,22.7,24.0,26.3,29.1,29.4,29.5$, $29.6,31.8,33.1,43.0,43.0,67.5,67.8,68.2,69.7,70.1$, $74.1,95.1,128.1,128.3,128.4,128.6,128.7,128.7,135.6$, 136.2, 137.3, 157.0, 170.5, 211.9 .

\section{(2S,3R)-2-Benzyloxycarbonylamino-2-}

benzyloxymethoxymethyl-12-oxo-3-sulfooxyoctadecanoic Acid Benzyl Ester (25a)

To a solution of alcohol 24a $(11 \mathrm{mg}, 0.016 \mathrm{mmol})$ in pyridine $(1 \mathrm{ml})$ was added $\mathrm{SO}_{3}$-pyridine complex $(25 \mathrm{mg}$, $0.16 \mathrm{mmol}$ ) at room temperature. After stirring at $80^{\circ} \mathrm{C}$ for 2 hour, the reaction mixture was diluted with $\mathrm{MeOH}$ at room temperature. Removal of the solvent gave a residue, which was purified by flash chromatography ( $1 \mathrm{~g}$ silica gel, $1 / 10 \mathrm{MeOH} / \mathrm{CHCl}_{3}$ as an eluent) afforded 25a (12 mg, quant.) as a colorless syrup; $[\alpha]_{\mathrm{D}}^{23}+12^{\circ}(c 0.80, \mathrm{MeOH})$; IR $v_{\max }$ (neat) $3420,2930,2855,1735,1720,1710,1505$, 1455, 1260, 1230, 1050, 1030, $960 \mathrm{~cm}^{-1}$; HR FAB-MS m/z for $\mathrm{C}_{42} \mathrm{H}_{58} \mathrm{NO}_{11} \mathrm{~S}(\mathrm{M}-\mathrm{H})^{-}$, Calcd: 782.3574, Found:
782.3578; ${ }^{1} \mathrm{H}$ NMR $\left(300 \mathrm{MHz}, \mathrm{CD}_{3} \mathrm{OD}\right) \delta: 0.89(3 \mathrm{H}, \mathrm{t}$, $\left.J=6.3 \mathrm{~Hz}, \mathrm{CH}_{2} \mathrm{CH}_{3}\right), 1.02 \sim 1.62\left(22 \mathrm{H}, \mathrm{m}, 11 \times-\mathrm{CH}_{2}-\right)$, $2.42(2 \mathrm{H}, \mathrm{t}, J=7.3 \mathrm{~Hz}, \mathrm{H}-11), 2.43$ (2H, t $J=7.3 \mathrm{~Hz}, \mathrm{H}-13)$, $4.20\left(2 \mathrm{H}, \mathrm{s},-\mathrm{C}_{2} \mathrm{OBOM}\right), 4.48(1 \mathrm{H}, \mathrm{d}, J=11.7 \mathrm{~Hz}$, $\left.-\mathrm{C}_{\mathrm{HHOCH}} \mathrm{Ph}\right), 4.52\left(1 \mathrm{H}, \mathrm{d}, J=11.7 \mathrm{~Hz},-\mathrm{CH}^{\mathrm{HOCH}}{ }_{2} \mathrm{Ph}\right)$, $4.66\left(2 \mathrm{H}, \mathrm{s},-\mathrm{CH}_{2} \mathrm{OC} \underline{H}_{2} \mathrm{Ph}\right), 4.76(1 \mathrm{H}, \mathrm{d}, J=8.7 \mathrm{~Hz}, \mathrm{H}-3)$, $5.02\left(2 \mathrm{H}, \mathrm{s},-\mathrm{NHCO}_{2} \underline{\mathrm{C}}_{2} \mathrm{Ph}\right), 5.10(1 \mathrm{H}, \mathrm{d}, J=12.3 \mathrm{~Hz}$, $\left.-\mathrm{CCO}_{2} \mathrm{CH} H \mathrm{HP}\right), 5.24\left(1 \mathrm{H}, \mathrm{d}, J=12.3 \mathrm{~Hz},-\mathrm{CCO}_{2} \mathrm{CH} \underline{H P h}\right)$, $7.18 \sim 7.42(15 \mathrm{H}, \mathrm{m}, \mathrm{Ph}) ;{ }^{13} \mathrm{C}$ NMR $\left(75 \mathrm{MHz}, \mathrm{CD}_{3} \mathrm{OD}\right) \delta$ : $14.4,23.6,24.9,24.9,26.9,30.0,30.3,30.3,30.4,30.4$, $32.5,32.8,43.5,67.0,67.4,68.5,70.2,81.4,95.7,128.6$, $128.8,129.0,129.2,129.3,129.4,129.4,129.6,129.7$, $136.9,138.2,139.3,157.0,171.4,214.4$.

\section{$(+)$-Sulfamisterin (1)}

To a solution of 25a (12 mg, $0.016 \mathrm{mmol})$ in $\mathrm{MeOH}(1 \mathrm{ml})$ was added $20 \% \mathrm{Pd}(\mathrm{OH})_{2}$ on activated carbon $(10 \mathrm{mg})$ at room temperature and the mixture was hydrogenated under atmospheric pressure of $\mathrm{H}_{2}$ for 15 hour. The insoluble material was removed by filtration through celite and the filtrate was concentrated to give a residue, which was purified by a column of Sephadex LH-20 $(95 \mathrm{ml}, \mathrm{MeOH}$ as an eluent). The fractions containing 1 were collected and concentrated to give a residue, which was treated with IRC76 resin $\left(\mathrm{H}^{+}\right.$form $)$. The resin was removed by filtration and the filtrate was concentrated to afford $(+)$-sulfamisterin (1) $(3.0 \mathrm{mg}, 57 \%)$ as white solids; $[\alpha]_{\mathrm{D}}^{21}+3.6^{\circ}(c 0.62, \mathrm{MeOH})$ \{natural sulfamisterin: lit. $[1][\alpha]_{\mathrm{D}}^{23}+2.0^{\circ}(c 1.0, \mathrm{MeOH})$; $[\alpha]_{\mathrm{D}}^{28}+3.1^{\circ}(c 0.50, \mathrm{MeOH})$, measured in our laboratory $\}$; IR $v_{\max }$ (neat) $3435,2930,2855,1710,1660,1645,1520$, $1405,1385,1290,1230,1060 \mathrm{~cm}^{-1}$; HR FAB-MS $m / z$ for $\mathrm{C}_{19} \mathrm{H}_{36} \mathrm{NO}_{8} \mathrm{~S}(\mathrm{M}-\mathrm{H})^{-}$, Calcd: 438.2161, Found: 438.2171; ${ }^{1} \mathrm{H}$ NMR $\left(300 \mathrm{MHz}, \mathrm{CD}_{3} \mathrm{OD}\right) \delta: 0.90(3 \mathrm{H}, \mathrm{t}, J=6.6 \mathrm{~Hz}$, $\left.\mathrm{CH}_{2} \mathrm{CH}_{3}\right), 1.28 \sim 1.90\left(22 \mathrm{H}, \mathrm{m}, 11 \times-\mathrm{CH}_{2}-\right), 2.43(2 \mathrm{H}, \mathrm{t}$, $J=7.2 \mathrm{~Hz}, \mathrm{H}-11), 2.44(2 \mathrm{H}, \mathrm{t}, J=7.2 \mathrm{~Hz}, \mathrm{H}-13), 3.84(1 \mathrm{H}$, $\mathrm{d}, J=11.7 \mathrm{~Hz},-\mathrm{C} \underline{\mathrm{H} H O H}), 4.12(1 \mathrm{H}, \mathrm{d}, J=11.7 \mathrm{~Hz}$, $-\mathrm{CH} \underline{\mathrm{HOH}}), 4.60(1 \mathrm{H}, \mathrm{dd}, J=9.8, J=2.7 \mathrm{~Hz}, \mathrm{H}-3) ;{ }^{13} \mathrm{C}$ NMR $\left(75 \mathrm{MHz}, \mathrm{CD}_{3} \mathrm{OD}\right) \delta: 14.4,23.6,24.9,24.9,26.9$, $30.0,30.3,30.4,30.4,30.5,32.0,32.8,43.5,43.5,61.2$, 69.6, 79.6, 171.2, 214.4. The ${ }^{1} \mathrm{H}$ and ${ }^{13} \mathrm{C}$ NMR data were fully identical with those of natural sulfamisterin.

\section{(2R,3R)-2-Benzyloxycarbonylamino-3-hydroxy-2-} hydroxymethyl-12-oxo-octadecanoic Acid Benzyl Ester (26a)

By the same reaction conditions as described for the preparation of 23a from 21a, compound 22a (47 mg, $0.07 \mathrm{mmol}$ ) was converted to diol 26a (33 $\mathrm{mg}, 56 \%$ for 4 steps); a colorless syrup; $[\alpha]_{\mathrm{D}}^{21}+18^{\circ}\left(c 1.01, \mathrm{CHCl}_{3}\right)$; IR 
$v_{\max }$ (neat) 3405, 2930, 2850,1730, 1705, 1510, 1455, $1275,1220,1060,1030 \mathrm{~cm}^{-1}$; HR FAB-MS $\mathrm{m} / \mathrm{z}$ for $\mathrm{C}_{34} \mathrm{H}_{50} \mathrm{NO}_{7}(\mathrm{M}+\mathrm{H})^{+}$, Calcd: 584.3587, Found: 584.3589; Anal Found: C, 69.66; H, 8.39; N, 2.37\%. Calcd for $\mathrm{C}_{34} \mathrm{H}_{49} \mathrm{NO}_{7}$ : C, 69.95; $\mathrm{H}, 8.46 ; \mathrm{N}, 2.40 \% ;{ }^{1} \mathrm{H}$ NMR $\left(300 \mathrm{MHz}, \mathrm{CDCl}_{3}\right) \delta: 0.88\left(3 \mathrm{H}, \mathrm{t}, J=6.6 \mathrm{~Hz}, \mathrm{CH}_{2} \mathrm{C}_{3}\right)$, $1.04 \sim 1.62\left(22 \mathrm{H}, \mathrm{m}, 11 \times-\mathrm{CH}_{2}-\right), 2.29(1 \mathrm{H}, \mathrm{bs}, \mathrm{OH})$, $2.37(2 \mathrm{H}, \mathrm{t}, J=7.2 \mathrm{~Hz}, \mathrm{H}-11), 2.38(2 \mathrm{H}, \mathrm{t}, J=7.2 \mathrm{~Hz}$, $\mathrm{H}-13), 4.00 \sim 4.32\left(4 \mathrm{H}, \mathrm{m},-\mathrm{C}_{2}{ }_{2} \mathrm{OH}, \mathrm{H}-3, \mathrm{OH}\right), 5.07$ $\left(1 \mathrm{H}, \quad\right.$ d, $\left.J=12.3 \mathrm{~Hz},-\mathrm{NHCO}_{2} \mathrm{C} \underline{\mathrm{H}} \mathrm{HPh}\right), 5.12(1 \mathrm{H}, \mathrm{d}$, $\left.J=12.3 \mathrm{~Hz},-\mathrm{NHCO}_{2} \mathrm{CH} \underline{\mathrm{HPh}}\right), 5.18(1 \mathrm{H}, \mathrm{d}, J=12.0 \mathrm{~Hz}$, $\left.-\mathrm{CCO}_{2} \mathrm{C} \underline{H} H \mathrm{Ph}\right), 5.28\left(1 \mathrm{H}, \mathrm{d}, J=12.0 \mathrm{~Hz},-\mathrm{CCO}_{2} \mathrm{CH} \underline{\mathrm{HPh}}\right)$, $6.10(1 \mathrm{H}, \mathrm{s}, \mathrm{NH}), 7.32 \sim 7.38(10 \mathrm{H}, \mathrm{m}, \mathrm{Ph}) ;{ }^{13} \mathrm{C} \mathrm{NMR}$ $\left(75 \mathrm{MHz}, \mathrm{CDCl}_{3}\right) \delta: 14.2,22.7,24.0,26.0,29.1,29.4,29.5$, 29.5, 31.8, 33.0, 43.0, 43.0, 64.3, 67.6, 68.3, 69.3, 74.4, $128.3,128.6,128.8,128.8,135.0,135.9,156.8,171.2$, 212.0.

\section{(2R,3R)-2-Benzyloxycarbonylamino-2-}

benzyloxymethoxymethyl-3-hydroxy-12-oxo-

octadecanoic Acid Benzyl Ester (27a)

By the same reaction conditions as described for the preparation of 24a from 23a, compound 26a ( $80 \mathrm{mg}$, $0.138 \mathrm{mmol})$ was converted to $\mathrm{BOM}$ ether $27 \mathrm{a}(81 \mathrm{mg}$, $83 \%$ ); colorless syrup; $[\alpha]_{\mathrm{D}}^{22}+8.9^{\circ}\left(c 1.35, \mathrm{CHCl}_{3}\right)$; IR $v_{\max }$ (neat) $3410,2930,2855,1740,1705,1505,1455$, $1280,1250,1220,1050,1030 \mathrm{~cm}^{-1}$; HR FAB-MS $\mathrm{m} / \mathrm{z}$ for $\mathrm{C}_{42} \mathrm{H}_{58} \mathrm{NO}_{8}(\mathrm{M}+\mathrm{H})^{+}$, Calcd: 704.4162, Found: 704.4175; ${ }^{1} \mathrm{H} \mathrm{NMR}\left(300 \mathrm{MHz}, \mathrm{CDCl}_{3}\right) \delta: 0.88(3 \mathrm{H}, \mathrm{t}, J=6.6 \mathrm{~Hz}$, $\left.\mathrm{CH}_{2} \mathrm{C}_{3}\right), 1.00 \sim 1.62\left(22 \mathrm{H}, \mathrm{m}, 11 \times-\mathrm{CH}_{2}-\right), 2.37(2 \mathrm{H}, \mathrm{t}$, $J=7.2 \mathrm{~Hz}, \mathrm{H}-11), 2.38 \quad(2 \mathrm{H}, \mathrm{t}, \quad J=7.2 \mathrm{~Hz}, \mathrm{H}-13)$, $4.04(1 \mathrm{H}, \mathrm{dt}, J=2.4, J=10.5 \mathrm{~Hz}, \mathrm{H}-3), 4.10(1 \mathrm{H}, \mathrm{d}$, $J=10.2 \mathrm{~Hz},-$ ChHOBOM), $4.33(1 \mathrm{H}, \mathrm{d}, J=10.2 \mathrm{~Hz}$, $-\mathrm{CH} \underline{\mathrm{HOBOM}}), 4.42\left(2 \mathrm{H}, \mathrm{s},-\mathrm{C}_{2} \mathrm{OCH}_{2} \mathrm{Ph}\right), 4.61(1 \mathrm{H}, \mathrm{d}$, $\left.J=6.6 \mathrm{~Hz},-\mathrm{CH}_{2} \mathrm{OC} \underline{\mathrm{H} H P h}\right), 4.64(1 \mathrm{H}, \quad \mathrm{d}, J=6.6 \mathrm{~Hz}$, $\left.-\mathrm{CH}_{2} \mathrm{OCH} \underline{\mathrm{HPh}}\right), 4.67(1 \mathrm{H}, \mathrm{d}, J=10.5 \mathrm{~Hz}, \mathrm{OH}), 5.02$ $\left(1 \mathrm{H}, \mathrm{d}, J=12.3 \mathrm{~Hz},-\mathrm{NHCO}_{2} \mathrm{C} \underline{\mathrm{H} H P h}\right), 5.10(1 \mathrm{H}, \mathrm{d}$, $\left.J=12.3 \mathrm{~Hz},-\mathrm{NHCO}_{2} \mathrm{CH} \underline{\mathrm{HPh}}\right), 5.15(1 \mathrm{H}, \mathrm{d}, J=12.0 \mathrm{~Hz}$, $\left.-\mathrm{CCO}_{2} \mathrm{C} \underline{H} H \mathrm{Ph}\right), 5.27\left(1 \mathrm{H}, \mathrm{d}, J=12.0 \mathrm{~Hz},-\mathrm{CCO}_{2} \mathrm{CH} \underline{H P h}\right)$, $6.28(1 \mathrm{H}, \mathrm{s}, \mathrm{NH}), 7.23 \sim 7.36(15 \mathrm{H}, \mathrm{m}, \mathrm{Ph}) ;{ }^{13} \mathrm{C} \mathrm{NMR}$ $\left(75 \mathrm{MHz}, \mathrm{CDCl}_{3}\right) \delta: 14.0,22.5,23.9,25.8,29.0,29.3,29.4$, $31.6,33.1,42.8,42.8,67.3,68.1,68.7,68.9,69.3,74.6$, $94.6,127.7,127.8,128.0,128.3,128.4,128.5,128.5$, $128.6,128.7,134.8,135.9,137.5,156.7,170.7,211.7$.

\section{(2R,3R)-2-Benzyloxycarbonylamino-2-}

benzyloxymethoxymethyl-12-oxo-3-sulfooxyoctadecanoic Acid Benzyl Ester (28a)

By the same reaction conditions as described for the preparation of 25a from 24a, compound 27a (20 mg, $0.028 \mathrm{mmol}$ ) was converted to sulfate $\mathbf{2 8 a}$ ( $23 \mathrm{mg}$, quant.); colorless syrup; $[\alpha]_{\mathrm{D}}^{23}+14^{\circ}(c 1.08, \mathrm{MeOH})$; IR $v_{\max }$ (neat) 3400, 2930, 2855, 1730, 1715, 1700, 1520, 1505, $1455,1290,1220,1050 \mathrm{~cm}^{-1}$; HR FAB-MS $\mathrm{m} / \mathrm{z}$ for $\mathrm{C}_{42} \mathrm{H}_{56} \mathrm{NO}_{11} \mathrm{~S}(\mathrm{M}-\mathrm{H})^{-}$, Calcd: 782.3574, Found: 782.3573; ${ }^{1} \mathrm{H}$ NMR $\left(300 \mathrm{MHz}, \mathrm{CD}_{3} \mathrm{OD}\right) \delta: 0.89(3 \mathrm{H}, \mathrm{t}, J=6.6 \mathrm{~Hz}$, $\left.\mathrm{CH}_{2} \mathrm{CH}_{3}\right), 1.08 \sim 1.74\left(22 \mathrm{H}, \mathrm{m}, 11 \times-\mathrm{CH}_{2}-\right), 2.41(2 \mathrm{H}, \mathrm{t}$, $J=7.5 \mathrm{~Hz}, \mathrm{H}-11), 2.42(2 \mathrm{H}, \mathrm{t}, J=7.5 \mathrm{~Hz}, \mathrm{H}-13), 4.01(1 \mathrm{H}$, d, $J=10.2 \mathrm{~Hz},-$ C $\underline{H}$ HOBOM), $4.38(1 \mathrm{H}, \mathrm{d}, J=10.2 \mathrm{~Hz}$, $-\mathrm{CH} \underline{\mathrm{HOBOM}}), 4.52\left(2 \mathrm{H}, \mathrm{s},-\mathrm{C}_{2} \mathrm{OCH}_{2} \mathrm{Ph}\right), 4.67(1 \mathrm{H}$, d, $\left.J=6.9 \mathrm{~Hz},-\mathrm{CH}_{2} \mathrm{OC} \underline{\mathrm{H} H P h}\right), 4.73(1 \mathrm{H}, \mathrm{d}, J=6.9 \mathrm{~Hz}$, $\left.-\mathrm{CH}_{2} \mathrm{OCH} \underline{\mathrm{HPh}}\right), 4.81(1 \mathrm{H}, \mathrm{dd}, J=1.8,8.7 \mathrm{~Hz}, \mathrm{H}-3)$, $4.91\left(1 \mathrm{H}, \mathrm{d}, J=12.3 \mathrm{~Hz},-\mathrm{NHCO}_{2} \mathrm{CH} H \mathrm{Hh}\right), 4.99(1 \mathrm{H}, \mathrm{d}$, $\left.J=12.3 \mathrm{~Hz},-\mathrm{NHCO}_{2} \mathrm{CH} \underline{\mathrm{HPh}}\right), 5.15\left(2 \mathrm{H}, \mathrm{s},-\mathrm{CCO}_{2} \underline{\mathrm{C}}_{2} \mathrm{Ph}\right)$, $7.18 \sim 7.42(15 \mathrm{H}, \mathrm{m}, \mathrm{Ph}) ;{ }^{13} \mathrm{C}$ NMR $\left(75 \mathrm{MHz}, \mathrm{CD}_{3} \mathrm{OD}\right) \delta$ : 14.4, 23.6, 24.9, 24.9, 26.9, 30.0, 30.3, 30.4, 30.5, 30.5, $31.8,32.8,43.5,67.3,67.4,68.2,70.4,79.2,79.3,95.8$, $128.7,128.8,128.9,129.1,129.2,129.4,129.4,129.5$, 137.1, 138.1, 139.2, 157.4, 171.0, 214.4.

\section{$(2 R, 3 R)$-Sulfamisterin (3-epi-sulfamisterin) (2)}

By the same reaction conditions as described for the preparation of sulfamisterin (1) from 25a, compound 28a $(23 \mathrm{mg}, \quad 0.028 \mathrm{mmol})$ was converted to $(2 R, 3 R)$ sufamisterin (2) (7.4 mg, 58\%); white solid; $[\alpha]_{\mathrm{D}}^{23}+5.6^{\circ}$ (c $0.70, \mathrm{CHCl}_{3}$ ); IR $v_{\max }$ (neat) 3420, 2930, 2860, 1710, $1650,1635,1510,1470,1410,1260,1220,1060 \mathrm{~cm}^{-1}$; HR FAB-MS $m / z$ for $\mathrm{C}_{19} \mathrm{H}_{36} \mathrm{NO}_{8} \mathrm{~S}(\mathrm{M}-\mathrm{H})^{-}$, Calcd: 438.2152, Found: $438.2152 ;{ }^{1} \mathrm{H}$ NMR $\left(300 \mathrm{MHz}, \mathrm{CD}_{3} \mathrm{OD}\right) \delta$ : $0.90\left(3 \mathrm{H}, \mathrm{t}, J=6.6 \mathrm{~Hz}, \mathrm{CH}_{2} \underline{\mathrm{C}}_{\underline{3}}\right), 1.28 \sim 1.80(22 \mathrm{H}, \mathrm{m}$, $\left.11 \times-\mathrm{CH}_{2}-\right), 2.44(4 \mathrm{H}, \mathrm{t}, J=7.2 \mathrm{~Hz}, \mathrm{H}-11, \mathrm{H}-13), 3.98(1 \mathrm{H}$, d, $J=11.7 \mathrm{~Hz},-\mathrm{C} \underline{\mathrm{H} H O H}), 4.04(1 \mathrm{H}, \mathrm{d}, J=11.7 \mathrm{~Hz}$, $-\mathrm{CH} \underline{\mathrm{HOH}}), 4.68(1 \mathrm{H}, \mathrm{dd}, J=9.8, J=2.5 \mathrm{~Hz}, \mathrm{H}-3) ;{ }^{13} \mathrm{C}$ NMR (75 MHz, $\left.\mathrm{CD}_{3} \mathrm{OD}\right) \delta: 14.4,23.6,24.9,24.9,26.7$, $30.0,30.3,30.4,30.4,30.5,32.0,32.8,43.5,43.5,64.3$, 70.3, 79.0, 170.7, 214.4 .

\section{(2S,3R)-3-Hydroxy-2-hydroxymethyl-12-oxo-2-(2,2,2-} trichloro-acetylamino)-octadecanoic Acid Methyl Ester (29a)

Ozone was introduced into a solution of carbamate 19a $(114 \mathrm{mg}, 0.199 \mathrm{mmol})$ in $\mathrm{MeOH}(3.4 \mathrm{ml})$ at $-78^{\circ} \mathrm{C}$ for 15 minutes. After purging of excess ozone with a stream of $\mathrm{Ar}$ gas, to the solution was added $\mathrm{Me}_{2} \mathrm{~S}(0.15 \mathrm{ml}, 1.99 \mathrm{mmol})$ and the mixture was stirred at $-78^{\circ} \mathrm{C}$ for 1 hour. The resulting mixture was diluted with EtOAc and washed with brine, and dried. Removal of the solvent gave crude aldehyde $(114 \mathrm{mg})$ as a yellow syrup. To a solution of the 
crude aldehyde in $t$ - $\mathrm{BuOH}(1.7 \mathrm{ml})$ and water $(1.7 \mathrm{ml})$ were added $\mathrm{NaH}_{2} \mathrm{PO}_{4} \cdot 2 \mathrm{H}_{2} \mathrm{O}(62.1 \mathrm{mg}, 0.398 \mathrm{mmol}), \mathrm{HOSO}_{2} \mathrm{NH}_{2}$ (58.0 mg, $0.597 \mathrm{mmol})$ and $\mathrm{NaClO}_{2}(54.0 \mathrm{mg}, 0.597 \mathrm{mmol})$ at room temperature. After stirring for 24 hour at room temperature the reaction mixture was quenched with $20 \mathrm{wt} \%$ aq solution of $\mathrm{Na}_{2} \mathrm{~S}_{2} \mathrm{O}_{3}$. The aq phase was extracted with $\mathrm{CHCl}_{3}(\times 5)$. The combined organic layer was washed with $20 \mathrm{wt} \%$ aq solution of $\mathrm{Na}_{2} \mathrm{~S}_{2} \mathrm{O}_{3}$, and dried. Removal of the solvent afforded crude carboxylic acid $(125 \mathrm{mg})$ as white solids. To a solution of the crude carboxylic acid $(125 \mathrm{mg})$ in $\mathrm{MeOH} /$ benzene $(3.8 \mathrm{ml}, 1 / 4)$ was added $\mathrm{Me}_{3} \mathrm{SiCHN}_{2}(2.0 \mathrm{~mol} /$ liter in hexane, $0.13 \mathrm{ml}, 0.259 \mathrm{mmol})$ at room temperature. The mixture was stirred for 13 hour at room temperature and concentrated to give a residue, which was purified by chromatography ( $6 \mathrm{~g}$ silica gel, $1 / 10$ to $1 / 5 \mathrm{EtOAc/hexane}$ as an eluent) to afford methyl ester $(87.4 \mathrm{mg})$ as a colorless syrup. To a solution of the methyl ester $(87.4 \mathrm{mg})$ in THF $(2.2 \mathrm{ml})$ was added $6 \mathrm{~N} \mathrm{HCl}$ aq $(1.1$ $\mathrm{ml})$ at $0^{\circ} \mathrm{C}$, and the mixture was stirred at room temperature for 5 hour. The reaction mixture was diluted with $\mathrm{CHCl}_{3}$ and washed with brine, and dried. Removal of the solvent gave a residue, which was purified by column chromatography (6 $\mathrm{g}$ silila gel, 1/6 EtOAc/toluene as an eluent) to afford diol 29a (59 mg, 57\% for 4 steps) as a syrup; $[\alpha]_{\mathrm{D}}^{24}+14^{\circ}\left(c 1.09, \mathrm{CHCl}_{3}\right)$; IR $v_{\max }$ (neat) 3370 , 2930, 2855, 1750, 1715, 1515, 1460, 1375, 1230, $1035 \mathrm{~cm}^{-1}$; HR FAB-MS $m / z$ for $\mathrm{C}_{22} \mathrm{H}_{39} \mathrm{Cl}_{3} \mathrm{NO}_{6}(\mathrm{M}+\mathrm{H})^{+}$, Calcd: 518.1843, Found: 518.1833; ${ }^{1} \mathrm{H}$ NMR $\left(300 \mathrm{MHz}, \mathrm{CDCl}_{3}\right)$ $\delta: 0.86\left(3 \mathrm{H}, \mathrm{t}, J=6.5 \mathrm{~Hz}, \mathrm{CH}_{2} \mathrm{CH}_{3}\right), 1.36 \sim 1.53(22 \mathrm{H}, \mathrm{m}$, $\left.11 \times-\mathrm{CH}_{2}-\right), 2.37(4 \mathrm{H}, \mathrm{t}, J=7.4 \mathrm{~Hz}, \mathrm{H}-11, \mathrm{H}-13), 3.81(3 \mathrm{H}$, s, $\left.\mathrm{CO}_{2} \underline{\mathrm{C}}_{3}\right), 4.03(1 \mathrm{H}, \mathrm{bt}, J=6.1 \mathrm{~Hz}, \mathrm{H}-3), 4.08(1 \mathrm{H}, \mathrm{d}$, $J=11.9 \mathrm{~Hz},-\mathrm{C} \underline{H} H O H), 4.18(1 \mathrm{H}, \mathrm{d}, J=11.9 \mathrm{~Hz},-\mathrm{CH} \underline{\mathrm{HOH}})$, $7.91(1 \mathrm{H}, \mathrm{s}, \mathrm{NH}) ;{ }^{13} \mathrm{C} \mathrm{NMR}\left(75 \mathrm{MHz}, \mathrm{CDCl}_{3}\right) \delta: 14.3$, 22.8, 24.1, 24.1, 26.1, 29.2, 29.4, 29.5, 30.3, 31.9, 32.0, $43.0,43.2,53.5,63.1,69.8,73.9,92.7,162.7,170.4,212.5$.

\section{Desulfonated Sulfamisterin (5)}

To a solution of 29a $(41 \mathrm{mg}, 0.079 \mathrm{mmol})$ in $\mathrm{MeOH}$ $(1.3 \mathrm{ml})$ was added $12 \mathrm{wt} \%$ aq $\mathrm{NaOH}$ solution $(0.6 \mathrm{ml})$ at room temperature. The mixture was stirred at $50^{\circ} \mathrm{C}$ for 18 hour, and then neutralized with IRC-76 resin $\left(\mathrm{H}^{+}\right.$form). The resin was removed by filtration through a glass filter, and the filtrate was concentrated to give a residue, which was purified by column chromatography $(3.5 \mathrm{~g}$ silica gel, $\mathrm{MeOH} / \mathrm{CHCl}_{3}=1 / 5$ as an eluent) to give roughly purified 5. This was further purified by gel filtration (Sephadex $\mathrm{LH}-20,95 \mathrm{ml}, \mathrm{MeOH}$ as an eluent) to afford desulfonated sufamisterin $(5)(15 \mathrm{mg}, 53 \%)$ as an amorphous solid; $[\alpha]_{\mathrm{D}}^{19}$ $+11^{\circ}$ (c 0.49, pyridine); IR $v_{\max }(\mathrm{KBr}$ disc) 3400, 2930, $2850,1710,1640,1540,1510,1470,1400,1385,1285$,
1130, $1050 \mathrm{~cm}^{-1}$; HR FAB-MS $\mathrm{m} / z$ for $\mathrm{C}_{19} \mathrm{H}_{38} \mathrm{NO}_{5}$ $(\mathrm{M}+\mathrm{H})^{+}$, Calcd: 360.2750, Found: 360.2764; ${ }^{1} \mathrm{H}$ NMR (300 MHz, CD $\left.\mathrm{CD}_{3} \mathrm{OD}\right) \delta: 0.90\left(3 \mathrm{H}, \mathrm{t}, J=6.7 \mathrm{~Hz}, \mathrm{CH}_{2} \underline{\mathrm{C}}_{\underline{3}}\right.$ ), $1.30 \sim 1.54\left(22 \mathrm{H}, \mathrm{m}, 11 \times-\mathrm{CH}_{2}-\right), 2.43(4 \mathrm{H}, \mathrm{t}, J=7.3 \mathrm{~Hz}$, $\mathrm{H}-11, \mathrm{H}-13), 3.80 \sim 3.86(1 \mathrm{H}, \mathrm{m}, \mathrm{H}-3), 3.80(1 \mathrm{H}$, d, $J=11.7 \mathrm{~Hz},-\underline{\mathrm{H} H O H}), 3.93(1 \mathrm{H}, \quad \mathrm{d}, J=11.7 \mathrm{~Hz}$, -CHHOH); ${ }^{13} \mathrm{C}$ NMR $\left(75 \mathrm{MHz}, \mathrm{CDCl}_{3}\right) \delta: 14.4,23.6,24.9$, $27.3,30.0,30.3,30.5,30.5,32.7,32.8,43.5,43.5,62.5$, $69.8,72.3,174.0,214.4$.

\section{(2R,3R)-3-Hydroxy-2-hydroxymethyl-12-0xo-2-(2,2,2- trichloro-acetylamino)-octadecanoic Acid Methyl Ester (30a)}

By the same reaction conditions as described for the preparation of 29a from 19a, compound 20a (142 mg, $0.249 \mathrm{mmol})$ was converted to diol $\mathbf{3 0 a}(90 \mathrm{mg}, 70 \%$ for 4 steps); colorless syrup; $[\alpha]_{\mathrm{D}}^{22}+3.1^{\circ}\left(c 0.47, \mathrm{CHCl}_{3}\right)$; IR $v_{\max }$ (neat) $3360,2930,2855,1715,1505,1455,1370$, 1290, 1230, 1160, 1125, 1075, $1040 \mathrm{~cm}^{-1}$; HR FAB-MS $m / z$ for $\mathrm{C}_{22} \mathrm{H}_{39} \mathrm{Cl}_{3} \mathrm{NO}_{6}(\mathrm{M}+\mathrm{H})^{+}$, Calcd: 518.1843, Found: $518.1859 ;{ }^{1} \mathrm{H}$ NMR $\left(300 \mathrm{MHz}, \mathrm{CDCl}_{3}\right) \delta: 0.86(3 \mathrm{H}, \mathrm{t}$, $\left.J=6.7 \mathrm{~Hz}, \mathrm{CH}_{2} \mathrm{CH}_{3}\right), 1.25 \sim 1.53\left(22 \mathrm{H}, \mathrm{m}, 11 \times-\mathrm{CH}_{2}-\right)$, $2.36(4 \mathrm{H}, \mathrm{t}, J=7.4 \mathrm{~Hz}, \mathrm{H}-11, \mathrm{H}-13), 3.86\left(3 \mathrm{H}, \mathrm{s}, \mathrm{CO}_{2} \underline{\mathrm{C}}_{\underline{3}}\right)$, $4.14 \sim 4.19(1 \mathrm{H}, \mathrm{m}, \mathrm{H}-3), 4.14(1 \mathrm{H}, \mathrm{d}, J=11.8 \mathrm{~Hz}$, $-\mathrm{C} \underline{\mathrm{H} H O H}), 4.28(1 \mathrm{H}, \mathrm{d}, J=11.8 \mathrm{~Hz},-\mathrm{CH} \underline{\mathrm{HOH}}), 8.11(1 \mathrm{H}$, $\mathrm{s}, \mathrm{NH}) ;{ }^{13} \mathrm{C}$ NMR $\left(75 \mathrm{MHz}, \mathrm{CDCl}_{3}\right) \delta: 14.0,22.5,23.8$, 23.8, 23.8, 25.6, 28.9, 29.1, 29.2, 29.2, 31.6, 32.6, 42.7, $42.8,53.7,63.0,70.7,73.5,92.3,162.6,170.9,211.9$.

\section{$(2 R, 3 R)$-Desulfonated Sulfamisterin (6)}

By the same reaction conditions as described for the preparation of $\mathbf{5}$ from 29a, compound 30a ( $90 \mathrm{mg}$, $0.174 \mathrm{mmol})$ was converted to $(2 R, 3 R)$-desulfonated sulfamisterin (6) (18 mg, 29\%); amorphous solid; $[\alpha]_{\mathrm{D}}^{20}$ $+8.2^{\circ}$ (c 0.49, pyridine); IR $v_{\max }(\mathrm{KBr}$ disc) 3400, 2930, 2850, 1710, 1630, 1510, 1470, 1415, 1380, 1320, 1285, $1130,1115,1090,1050 \mathrm{~cm}^{-1}$; HR FAB-MS $\mathrm{m} / z$ for $\mathrm{C}_{19} \mathrm{H}_{38} \mathrm{NO}_{5}(\mathrm{M}+\mathrm{H})^{+}$, Calcd: 360.2750, Found: 360.2751; ${ }^{1} \mathrm{H}$ NMR $\left(300 \mathrm{MHz}, \mathrm{CD}_{3} \mathrm{OD}\right) \delta: 0.90(3 \mathrm{H}, \mathrm{t}, J=5.8 \mathrm{~Hz}$, $\left.\mathrm{CH}_{2} \mathrm{CH}_{3}\right), 1.28 \sim 1.53\left(22 \mathrm{H}, \mathrm{m}, 11 \times-\mathrm{CH}_{2}-\right), 2.43(4 \mathrm{H}, \mathrm{t}$, $J=7.3 \mathrm{~Hz}, \mathrm{H}-11, \mathrm{H}-13), 3.81(1 \mathrm{H}, \mathrm{t}, J=6.3 \mathrm{~Hz}, \mathrm{H}-3), 3.83$ $(1 \mathrm{H}, \mathrm{d}, J=11.1 \mathrm{~Hz},-\mathrm{C} \underline{\mathrm{H} H O H}), 3.98(1 \mathrm{H}, \mathrm{d}, J=11.1 \mathrm{~Hz}$, -CHHOH); ${ }^{13} \mathrm{C} \mathrm{NMR}\left(75 \mathrm{MHz}, \mathrm{CDCl}_{3}\right) \delta: 14.4,23.6,24.9$, $27.4,30.3,30.3,30.5,30.5,32.6,32.8,43.5,64.8,71.1$, $71.5,173.5,214.4$.

\section{2-O-Benzyl-L-threitol (9b) (Enantiomer of 9a)}

To a solution of dimethyl L-tartrate $(30.0 \mathrm{~g}, 168 \mathrm{mmol})$ in 
$300 \mathrm{ml}$ of benzene at room temperature were added benzaldehyde dimethyl acetal $(27.8 \mathrm{ml}, 185 \mathrm{mmol})$ and $\mathrm{TsOH} \cdot \mathrm{H}_{2} \mathrm{O}(320 \mathrm{mg}, 1.68 \mathrm{mmol})$, and the mixture was heated at reflux for 2 days. After cooling to room temperature, the reaction mixture was neutralized with $0.3 \mathrm{ml}$ of $\mathrm{Et}_{3} \mathrm{~N}$ and diluted with EtOAc. The resulting mixture was washed with water and dried. Removal of the solvent afforded yellow crystal. Recrystallization from hexane gave pure benzylidene derivative $(42.3 \mathrm{~g}, 94 \%)$ as white crystals; m.p. $74 \sim 75^{\circ} \mathrm{C}$; $[\alpha]_{\mathrm{D}}^{19}-45^{\circ}($ c 2.19, MeOH$)$ \{lit. [8] m.p. $\left.70^{\circ} \mathrm{C} ;[\alpha]_{\mathrm{D}}-42^{\circ}\left(c \quad 0.50, \mathrm{CHCl}_{3}\right)\right\}$ To a suspension of $\mathrm{LiAlH}_{4}(8.3 \mathrm{~g}, 218 \mathrm{mmol})$ in diethyl ether $(100 \mathrm{ml})$ and $\mathrm{CH}_{2} \mathrm{Cl}_{2}(95 \mathrm{ml})$ was added the benzylidene derivative $(16.6 \mathrm{~g}, 62.3 \mathrm{mmol})$ at $0^{\circ} \mathrm{C}$. After stirring for 40 minutes, to the reaction mixture was added $\mathrm{AlCl}_{3}(25.0 \mathrm{~g}$, $187 \mathrm{mmol})$ in diethyl ether $(100 \mathrm{ml})$ dropwise at $0^{\circ} \mathrm{C}$, and the mixture was heated at reflux for 2.5 hour. After cooling to $0^{\circ} \mathrm{C}$, to the mixture were added with water $(20 \mathrm{ml})$, $15 \mathrm{wt} \% \mathrm{NaOH}$ aq $(100 \mathrm{ml})$ and water $(25 \mathrm{ml})$. The insoluble material was removed by filtration through celite (THF as an eluent), and the filtrate was dried. Removal of the solvent afforded crystalline residue, which was recrystallized from benzene to give $9 \mathrm{~b}(11.3 \mathrm{~g}, 86 \%)$ as white crystals; m.p. $75.5 \sim 76^{\circ} \mathrm{C} ;[\alpha]_{\mathrm{D}}^{24}+16^{\circ}$ (c 1.60, $\mathrm{MeOH})$. Spectral data were fully identical with those of $\mathbf{9 a}$.

Starting from $\mathbf{9 b}$, compounds $\mathbf{3}, \mathbf{4}, \mathbf{7}$, and $\mathbf{8}$ were synthesized by the same procedure as described for the preparation $\mathbf{1}, 2,5$, and 6 , respectively.

10b; m.p. $60 \sim 62^{\circ} \mathrm{C} ;[\alpha]_{\mathrm{D}}^{25}+59^{\circ}\left(c 0.40, \mathrm{CHCl}_{3}\right) . \mathbf{1 5 b}$; $[\alpha]_{\mathrm{D}}^{21}+3.4^{\circ}\left(c 1.52, \mathrm{CHCl}_{3}\right) \cdot \mathbf{1 6} \mathbf{b} ;[\alpha]_{\mathrm{D}}^{22}-78^{\circ}(c) 1.38$, $\left.\mathrm{CHCl}_{3}\right) . \mathbf{1 7} \mathbf{b} ;[\alpha]_{\mathrm{D}}^{23}-64^{\circ}\left(c 0.80, \mathrm{CHCl}_{3}\right) . \mathbf{1 9 b} ;[\alpha]_{\mathrm{D}}^{22}-22^{\circ}$ (c $\left.0.55, \mathrm{CHCl}_{3}\right) .20 \mathbf{b} ;[\alpha]_{\mathrm{D}}^{23}+20^{\circ}\left(c 0.69, \mathrm{CHCl}_{3}\right) . \mathbf{2 1} \mathbf{b}$; $[\alpha]_{\mathrm{D}}^{24}-14^{\circ}\left(c 1.09, \mathrm{CHCl}_{3}\right) . \mathbf{2 2 b} ;[\alpha]_{\mathrm{D}}^{23}+25^{\circ}(c$ 1.06, $\left.\mathrm{CHCl}_{3}\right) .23 \mathbf{b} ;[\alpha]_{\mathrm{D}}^{23}-5.1^{\circ}\left(c 0.97, \mathrm{CHCl}_{3}\right) \cdot 24 \mathrm{~b} ;[\alpha]_{\mathrm{D}}^{20}-37^{\circ}$ $\left(c 0.75, \mathrm{CHCl}_{3}\right) . \mathbf{2 5 b} ;[\alpha]_{\mathrm{D}}^{23}-11^{\circ}(c 0.94, \mathrm{MeOH}) .3 ;[\alpha]_{\mathrm{D}}^{27}$ $-4.5^{\circ}$ (c 0.55, MeOH). 26b; $[\alpha]_{\mathrm{D}}^{23}-16^{\circ}\left(c 0.55, \mathrm{CHCl}_{3}\right)$. $\mathbf{2 7 b} ;[\alpha]_{\mathrm{D}}^{22}-7.9^{\circ}\left(c 0.44, \mathrm{CHCl}_{3}\right) . \mathbf{2 8 b} ;[\alpha]_{\mathrm{D}}^{25}-12^{\circ}(c 0.38$, MeOH). 4; $[\alpha]_{\mathrm{D}}^{20}-5.3^{\circ}(c 0.41, \mathrm{MeOH}) .29 \mathrm{~b} ;[\alpha]_{\mathrm{D}}^{22}-14^{\circ}$ (c 1.11, $\left.\mathrm{CHCl}_{3}\right) .7$; $[\alpha]_{\mathrm{D}}^{23}-9.3^{\circ}$ (c 0.36, pyridine). 30b; $[\alpha]_{\mathrm{D}}^{22}-5.1^{\circ}\left(c \quad 1.18, \mathrm{CHCl}_{3}\right) .8 ;[\alpha]_{\mathrm{D}}^{19}-6.0^{\circ}(c) 0.43$, pyridine).

Acknowledgments We thank Dr. Atsushi Takahashi (Hokko Chemical Industry Co., Ltd., Toda, Japan) for generous gift of natural sulfamisterin. This work was supported by Grant-in-Aid for the 21st Century COE program "KEIO Life Conjugate Chemistry" from the Ministry of Education, Culture, Sports, Science, and Technology, Japan.

\section{References}

1. Tamamura T, Tetsuka Y, Takahashi A, Maruyama M, Sato K, Kuzuma S, Naganawa H, Takeuchi T. Fungicide and antibiotic AB5366 manufacture with Pycnidiella. JP08242873, September 24, 1996

2. Takahashi A, Tetsuka Y, Maruyama M, Kuzuma S, Tamamura T, Sato K, Naganawa H, Nakamura H, Takeuchi T. AB5366, a new antifungal antibiotic against Botrytis cinerea (in Japanese). Abstracts of Papers of the Annual Meeting of Japan Society for Bioscience, Biotechnology and Agrochemistry, 3A10p11, Nagoya, 1998

3. Yamaji-Hasegawa A, Takahashi A, Tetsuka Y, Senoh Y, Kobayashi T. Fungal metabolite sulfamisterin suppresses sphingolipid synthesis through inhibition of serine palmitoyltransferase. Biochemistry 44: 268-277 (2005)

4. Fujita T, Inoue K, Yamomoto S, Ikumoto T, Sasaki S, Toyama R, Chiba K, Hoshino Y, Okumoto T. Fungal metabolites. part 11. A portent immunosuppressive activity found in Isaria sinclairii metabolite. J. Antibiot 47: 208-215 (1994)

5. Miyake Y, Kozutsumi Y, Nakamura S, Fujita T, Kawasaki T. Serine palmitoyltransferase is the primary target of a sphingosine-like immunosuppressant, ISP-1/myriocin. Biochem Biophys Res Comm 211: 393-403 (1995)

6. Overman L. E. A general method for the synthesis of amines by the rearrangement of allylic trichloroacetimidates. 1,3 Transposition of alcohol and amine funcions. J Am Chem Soc 98: 2901-2910 (1976)

7. Oishi T, Ando K, Inomiya K, Sato H, Iida M, Chida N. Total synthesis of (+)-myriocin and (-)-sphingofungin $\mathrm{E}$ from aldohexoses using Overman rearrangement as the key reaction. Bull Chem Soc Jpn 75: 1927-1947 (2002)

8. Ohno M, Fujita K, Nakai H, Kobayashi S, Inoue K, Nojima S. An enantioselective synthesis of platelet-activating factors, their enantiomers, and their analogues from D- and L-tartaric acids. Chem Pharm Bull 33: 572-582 (1985)

9. Sánchez-Sancho F, Valverde S, Herradon B. Stereoselective syntheses and reactions of chiral oxygenated $\alpha, \beta$ unsaturated- $\gamma$-and $\delta$-lactones. Tetrahedron Asymmetry 7 : 3209-3246 (1996)

10. Payette DR, Just GA. Total synthesis of the enantiomer of anhydromyriocin (anhydrothermozymocidin). Can J Chem 59: 269-282 (1981)

11. Nishikawa $T$, Asai M, Ohyabu N, Isobe M. Improved conditions for facile Overman rearrangement. J Org Chem 63: 188-192 (1998)

12. Sanders WJ, Manning DD, Koeller KM, Kiessling LL. Synthesis of sulfated trisaccharide ligands for the selectins. Tetrahedron 53: 16391-16422 (1997) 